Prepared by the U.S. Geological Survey Office of Water Quality, National Water Quality Laboratory

\title{
Determination of Wastewater Compounds in Whole Water by Continuous Liquid-Liquid Extraction and Capillary-Column Gas Chromatography/Mass Spectrometry
}

\section{Chapter 4}

Section B, Methods of the National Water Quality Laboratory

Book 5, Laboratory Analysis

Techniques and Methods 5-B4
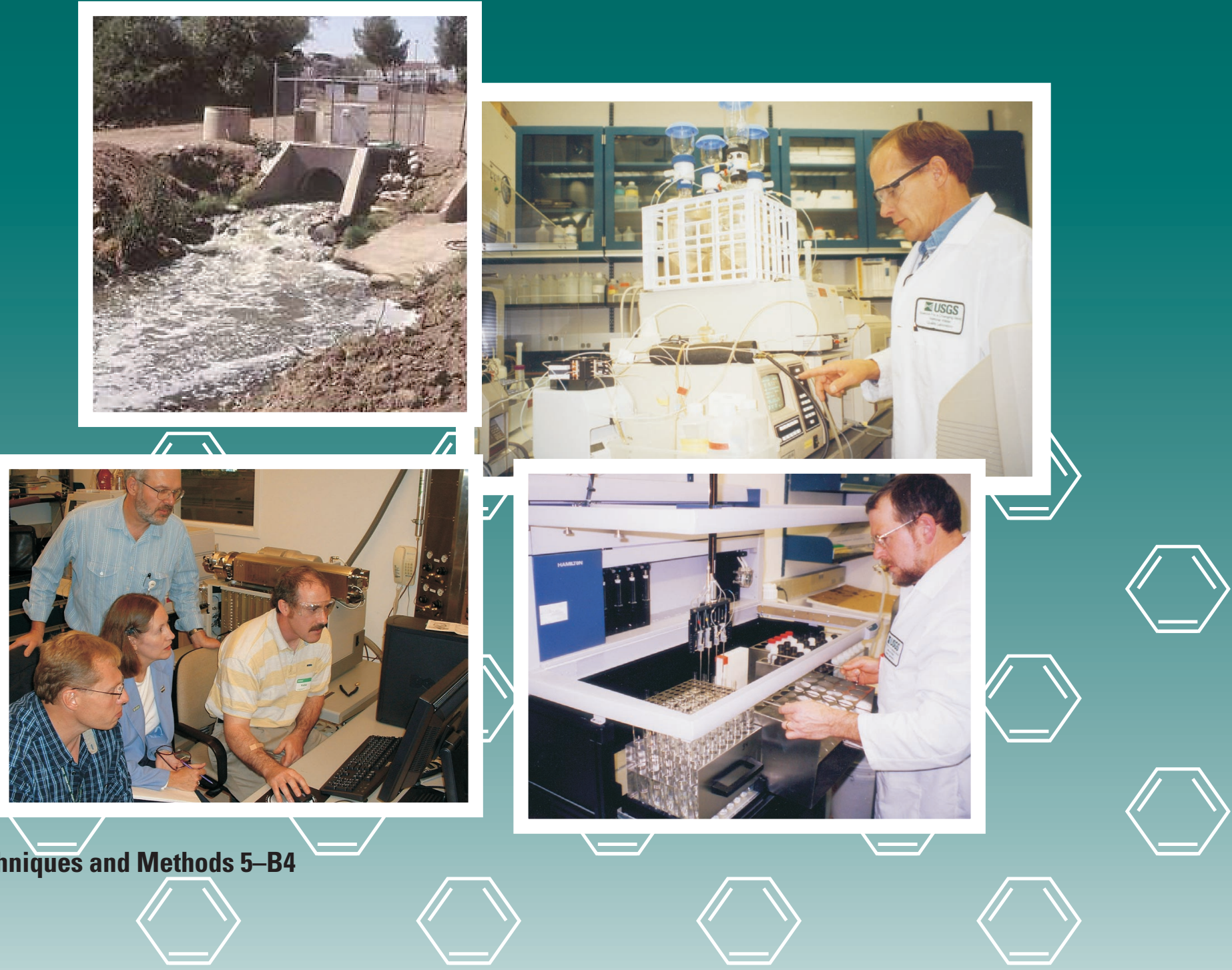

U.S. Department of the Interior U.S. Geological Survey 


\section{Determination of Wastewater Compounds in Whole Water by Continuous Liquid- Liquid Extraction and Capillary-Column Gas Chromatography/Mass Spectrometry}

By Steven D. Zaugg, Steven G. Smith, and Michael P. Schroeder

Chapter 4

Section B, Methods of the National Water Quality Laboratory

Book 5, Laboratory Analysis

Techniques and Methods 5-B4

U.S. Department of the Interior

U.S. Geological Survey 


\title{
U.S. Department of the Interior DIRK KEMPTHORNE, Secretary \\ U.S. Geological Survey \\ P. Patrick Leahy, Acting Director
}

\author{
U.S. Geological Survey, Reston, Virginia: 2006 \\ Revised: 2007
}

For product and ordering information:

World Wide Web: http://www.usgs.gov/pubprod

Telephone: 1-888-ASK-USGS

For more information on the USGS — the Federal source for science about the Earth, its natural and living resources, natural hazards, and the environment:

World Wide Web: http://www.usgs.gov

Telephone: 1-888-ASK-USGS

Any use of trade, product, or firm names is for descriptive purposes only and does not imply endorsement by the U.S. Government.

Although this report is in the public domain, permission must be secured from the individual copyright owners to reproduce any copyrighted materials contained within this report.

Suggested citation:

Zaugg, S.D., Smith, S.G., and Schroeder, M.P., 2006, Determination of wastewater compounds in whole water by continuous liquid-liquid extraction and capillary-column gas chromatography/mass spectrometry: U.S. Geological Survey Techniques and Methods, book 5, chap. B4, 30 p. 


\section{Contents}

Abstract

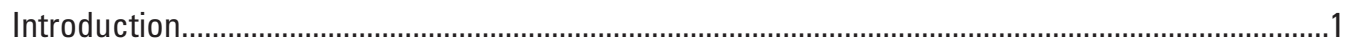

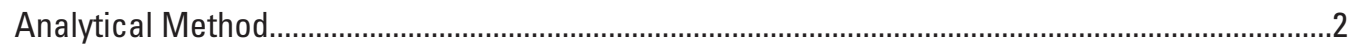

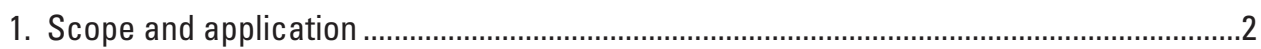

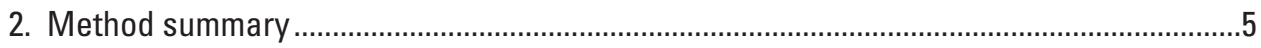

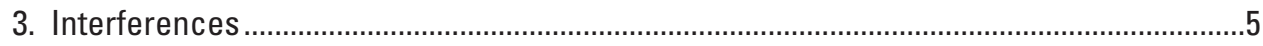

4. Apparatus and instrumentation..................................................................................

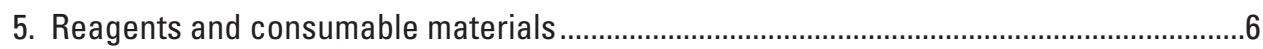

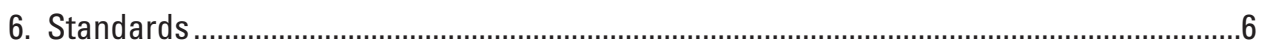

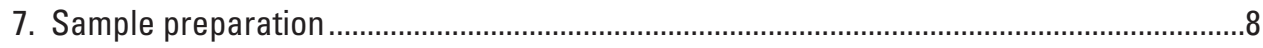

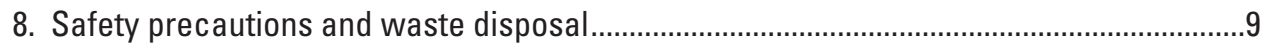

9. Gas chromatograph/mass spectrometer performance ….............................................10

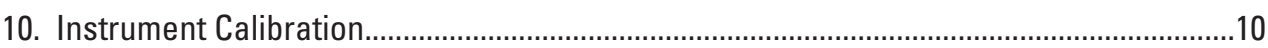

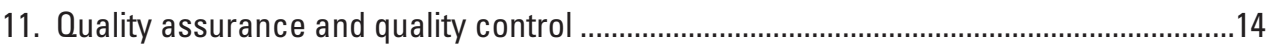

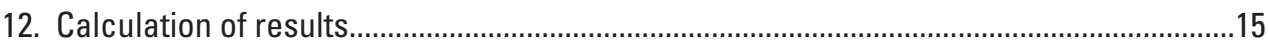

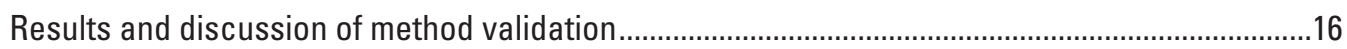

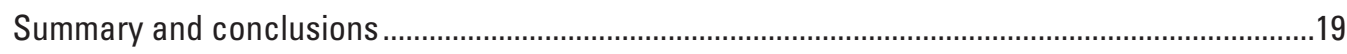

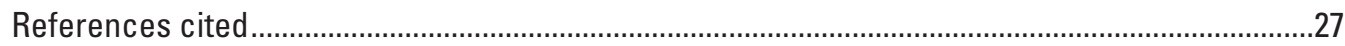

\section{Figures}

1. Continuous liquid-liquid extractors with solvent-dispersing frits mounted in a fume

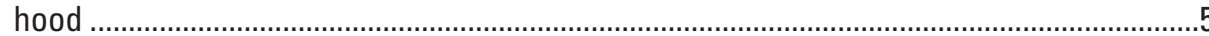

2. Manual integration of the extracted ion profile for the quantitation ion (mass-tocharge ratio 135) of 4-nonylphenol from the 2-nanogram-per-microliter calibration solution for the wastewater method

3. Boxplot showing results for analysis of 140 environmental whole-water samples ........26

\section{Tables}

1. Wastewater method compound names, endocrine-disrupting potential, log Kow, parameter/method codes, and possible compound uses...

2. Wastewater method compound retention time, quantitation ion, confirmation ions, surrogate compounds, and internal standard reference compound.

3. Typical analytical sequence suggested for use with this method ....................................15

4. Wastewater method compounds detected in unfortified reagent-water, ground-water, and surface-water samples

5. Wastewater method mean bias and variability of spike-recovery data for eight replicates with compounds spiked at two concentrations that range from 0.5 to 80 micrograms per liter in reagent-water (including calculated method detection limits), ground-water, and surface-water samples......

6. Wastewater initial method detection limits calculated from the spike-recovery data reported in table 5 using the eight replicate reagent-water samples with compound concentrations that range from 0.5 to 80 micrograms per liter 


\section{Conversion Factors}

\section{ISI to Inch/Pound}

\begin{tabular}{|c|c|c|}
\hline Multiply & By & To obtain \\
\hline \multicolumn{3}{|c|}{ Length } \\
\hline centimeter $(\mathrm{cm})$ & 0.3937 & inch (in.) \\
\hline micrometer $(\mu \mathrm{m})$ & 0.00003937 & inch (in.) \\
\hline millimeter (mm) & 0.03937 & inch (in.) \\
\hline meter $(\mathrm{m})$ & 39.37 & inch (in) \\
\hline \multicolumn{3}{|c|}{ Volume } \\
\hline liter (L) & 0.2642 & gallon (gal) \\
\hline microliter $(\mu \mathrm{L})$ & 0.000000264 & gallon (gal) \\
\hline milliliter (mL) & 0.000264 & gallon (gal) \\
\hline milliliter per minute $(\mathrm{mL} / \mathrm{min})$ & 0.0338 & ounce per minute \\
\hline \multicolumn{3}{|c|}{ Mass } \\
\hline $\operatorname{gram}(\mathrm{g})$ & 0.03527 & ounce, avoirdupois (oz) \\
\hline kilogram $(\mathrm{kg})$ & 2.205 & pound avoirdupois (lb) \\
\hline microgram $(\mu \mathrm{g})$ & 0.00000003527 & ounce, avoirdupois (oz) \\
\hline milligram (mg) & 0.00003527 & ounce, avoirdupois (oz) \\
\hline \multicolumn{3}{|c|}{ Pressure } \\
\hline kilopascal $(\mathrm{kPa})$ & 0.1450 & pound-force per inch (lbf/in) \\
\hline
\end{tabular}

Temperature in degrees Celsius $\left({ }^{\circ} \mathrm{C}\right)$ may be converted to degrees Fahrenheit $\left({ }^{\circ} \mathrm{F}\right)$ as follows:

${ }^{\circ} \mathrm{F}=\left(1.8 x^{\circ} \mathrm{C}\right)+32$

Temperature in degrees Fahrenheit $\left({ }^{\circ} \mathrm{F}\right)$ may be converted to degrees Celsius $\left({ }^{\circ} \mathrm{C}\right)$ as follows:

${ }^{\circ} \mathrm{C}=\left({ }^{\circ} \mathrm{F}-32\right) / 1.8$

\section{The following units of measurement are used in this report:}

in. inch

L/min liters per minute

$\min \quad$ minute

$\mathrm{mg} / \mathrm{mL} \quad$ milligram per milliliter

$\mu \mathrm{g} / \mathrm{L} \quad$ microgram per liter

$\mathrm{ng} / \mu \mathrm{L} \quad$ nanogram per microliter

\section{The following abbreviations and symbols are used in this report:}

AHTN acetyl-hexamethyl-tetrahydronaphthalene

AP alkylphenol

APEC alkylphenol ethoxycarboxylate

APE0 alkylphenol polyethoxylate

ASE accelerated solvent extraction

ASR analytical services request

CAS Chemical Abstracts Service 


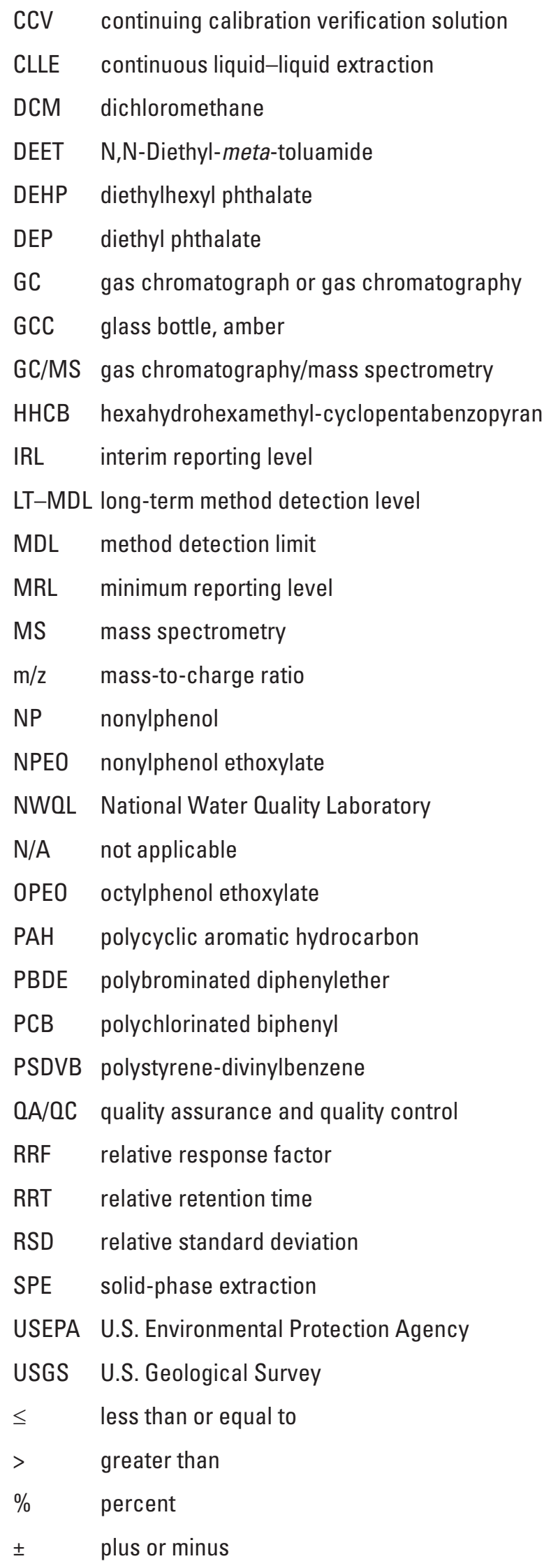




\title{
Determination of Wastewater Compounds in Whole Water by Continuous Liquid-Liquid Extraction and Capillary-Column Gas Chromatography/ Mass Spectrometry
}

\author{
By Steven D. Zaugg, Steven G. Smith, and Michael P. Schroeder
}

\section{Abstract}

A method for the determination of 69 compounds typically found in domestic and industrial wastewater is described. The method was developed in response to increasing concern over the impact of endocrine-disrupting chemicals on aquatic organisms in wastewater. This method also is useful for evaluating the effects of combined sanitary and storm-sewer overflow on the water quality of urban streams. The method focuses on the determination of compounds that are indicators of wastewater or have endocrine-disrupting potential. These compounds include the alkylphenol ethoxylate nonionic surfactants, food additives, fragrances, antioxidants, flame retardants, plasticizers, industrial solvents, disinfectants, fecal sterols, polycyclic aromatic hydrocarbons, and high-use domestic pesticides.

Wastewater compounds in whole-water samples were extracted using continuous liquid-liquid extractors and methylene chloride solvent, and then determined by capillarycolumn gas chromatography/mass spectrometry. Recoveries in reagent-water samples fortified at 0.5 microgram per liter averaged 72 percent \pm 8 percent relative standard deviation. The concentration of 21 compounds is always reported as estimated because method recovery was less than 60 percent, variability was greater than 25 percent relative standard deviation, or standard reference compounds were prepared from technical mixtures. Initial method detection limits averaged 0.18 microgram per liter. Samples were preserved by adding 60 grams of sodium chloride and stored at 4 degrees Celsius. The laboratory established a sample holding-time limit prior to sample extraction of 14 days from the date of collection.

\section{Introduction}

The United States faces the difficult challenge of effectively managing wastewater owing to limited water supply, increasing population, aging wastewater-treatment facilities and infrastructure, and emerging contaminants in the environment. Specific analytical methods are available (U.S. Environmental Protection Agency, 1995) to monitor regulated compounds in wastewater or the discharge from wastewatertreatment facilities. However, several unregulated compounds known to be toxic to aquatic life, such as nonylphenol ethoxylates (NPEOs), that are on the U.S. Environmental Protection Agency (USEPA) Toxic Substance Control Act Priority Testing List (U.S. Environmental Protection Agency, 1996), lack USEPA-approved analytical methods. To provide an analytical method for many unregulated compounds with known toxicity or endocrine-disrupting potential (U.S. Environmental Protection Agency, 1997a), the U.S. Geological Survey (USGS) National Water Quality Laboratory (NWQL) developed a method in 2001 to detect wastewater compounds in filtered water. This method uses polystyrene-divinylbenzene (PSDVB) solid-phase extraction (SPE) coupled with capillary-column gas chromatography/mass spectrometry (GC/MS) (Zaugg and others, 2002). This SPE method is appropriate for the analysis of wastewater compounds in filtered water, but in some cases (particularly surface-water samples) the analysis of wholewater (unfiltered) samples is desirable.

This report describes a method for determining a broad range of wastewater compounds in natural wholewater samples that complements the existing NWQL SPE method developed for filtered water. Whole-water samples are extracted by using continuous liquid-liquid extraction (CLLE) with methylene chloride (DCM) solvent, and compounds are determined by capillary-column GC/MS. This method requires less solvent and solvent exposure, and has far fewer emulsion problems than separatory-funnel methods currently (2006) in use at the NWQL. The method is similar to other methods that use CLLE and GC/MS for the determination of 4-tert-octylphenol, 4-nonylphenol, and bisphenol A in surface water (Jin and others, 2004), volatile compounds in wine (Castro and others, 2004), and polychlorinated biphenyls in blood plasma lipids (Wingfors and others, 2005). Other methods of the USGS (that do not use CLLE) have been used for the determination of organic substances in water and have been described previously by Wershaw and others (1987) and by Fishman (1993). However, a CLLE 
method at the NWQL to extract organophosphate pesticides from water has been approved for use since 2003 (Jha and Wydoski, 2003).

The CLLE wastewater method described in this report was implemented at the NWQL in October 1998 on a custom basis (Brown and others, 1999) as NWQL Laboratory Code 8033. A comparison of results for more than 30 environmental samples between the whole-water CLLE and the filteredwater SPE methods demonstrated that concentrations for some of the hydrophobic (low water-soluble) compounds having a log octanol-water partition coefficient (log Kow) greater than 3 were as much as 400 percent less when determined by SPE, presumably because of losses during sample filtration; whereas, results for hydrophilic compounds (log Kow less than 3) were comparable. The reproducibility of the method as evaluated using 47 other environmental samples had correlation coefficients greater than 0.95 for most of the compounds (Wilkison and others, 2002). This CLLE method has been used to describe urban sanitary-sewer and storm-sewer problems (Wilkison and others, 2002), as well as emerging contaminants in U.S. streams and runoff from concentrated animal feedlots for the USGS's Toxic Substances Hydrology Program (Kolpin and others, 2002). Results from using the method for 8 years (1998-2005) has demonstrated the capability for identifying anthropogenic contaminants over a wide range of sample matrices. The method officially was approved and implemented at the NWQL July 1, 2006, as analytical method O-1433-06.

This report provides a detailed description of all aspects of the method, including the equipment, reagents, sampling protocol, instrument calibration, and procedure required for sample analysis. Method performance (bias and variability) and estimated method detection limits for 69 compounds are presented.

The scope of this report includes determination of method performance in reagent-water, ground-water, and surfacewater samples. Method performance was determined at two appropriate concentrations for each compound ( 0.50 and 4.0 $\mu \mathrm{g} / \mathrm{L}$ for most compounds) in each water type. Method detection limits were determined according to an accepted statistical procedure (U.S. Environmental Protection Agency, 1997b).

\section{Analytical Method}

Organic Compounds and Parameter Codes: Wastewater compounds, whole water, gas chromatography/mass spectrometry, O-4433-06 (see table 1)

\section{Scope and Application}

This method is suitable for the determination of microgram-per-liter concentrations of compounds in whole wastewater and environmental water samples. The method is applicable to compounds that are efficiently partitioned from the water phase into the DCM organic phase, and are sufficiently volatile and thermally stable for gas chromatography.

The method includes many compounds that typically are associated with industrial and household wastewater (Paxéus and others, 1992), as well as some that are known or suspected endocrine-disrupting compounds (table 1).

The alkylphenol polyethoxylates (APEOs) are branchedchain nonionic surfactants that consist of the nonylphenol polyethoxylates (NPEOs) and the octylphenol polyethoxylates (OPEOs). The APEO surfactants generally contain up to about 20 ethoxy-units (Barber and others, 2000). The alkylphenol mono-ethoxylates (APEO1) are represented in the method by OPEO1 and NPEO1 (total, resulting from addition of several isomers). The alkylphenol di-ethoxylates are represented in the method by OPEO2 and NPEO2 (total) (see table 1). The degradation of APEOs in the environment can result in the formation of alkylphenols (APs) and alkylphenol ethoxycarboxylates (APEC). The APs are represented in the method (see table 1) by 4-cumylphenol, 4- $n$-octylphenol, 4-nonylphenol (total), and 4-tert-octylphenol. The APEOs also are degraded during sewage treatment (Geiger and others, 1984), and sewagetreatment-plant effluents can be major point sources for the APs and APECs. The APECs are too polar to be determined by this method because they thermally degrade on the GC. The volatility and availability of reference standard APEOs limit the method to the determination of OPEO1, OPEO2, NPEO1 (total), and NPEO2 (total), even though APEOs typically might contain up to about 20 ethoxy-units. However, most of the APEOs present in the environment after degradation contain less than four ethoxy-units. All of these compounds are known for their estrogenic activity in aquatic organisms (Jobling and Sumpter, 1993). A comprehensive analysis (Barber and others, 2000) of this family of compounds (APEOs and their degradates) is needed to understand their fate and transport in the environment.

Caffeine is an important indicator for surface-water contamination; however, it is not conservative in the environment because of rapid degradation by bacteria. Coprostanol has long been a traditional indicator of sewage contamination and is persistent in the environment under anaerobic conditions but is degraded by aerobic bacteria (Shigenaka and Price, 1988). Triclosan, an antimicrobial agent used in several common household products, and the synthetic polycyclic musk fragrance compounds acetyl-hexamethyl-tetrahydro-naphthalene (AHTN) and hexahydrohexamethyl-cyclopentabenzopyran (HHCB) are persistent in the environment and have been frequently detected during the custom implementation of this method. The presence and fate, as well as uses for the APEOs and other wastewater indicator compounds (caffeine, sterols, flame retardants, triclosan, AHTN, and HHCB), are described in more detail in Zaugg and others (2002).

The widespread detection of DEET by this method prior to method approval (1998-2002) also has been documented (Sandstrom and others, 2005). The polybrominated diphenylethers (PBDE), as well as other polybrominated flame-retarding chemicals, have the potential to become a widespread, persistent 
Table 1. Wastewater method compound names, endocrine-disrupting potential, log Kow, parameter/method codes, and possible compound uses.

[EDP, endocrine-disrupting potential; K, known; S, suspected; CAS, Chemical Abstract Service; F, fungicide; H, herbicide; I, insecticide; GUP, general use pesticide; FR, flame retardant; PAH, polycyclic aromatic hydrocarbon; Kow, octanol-water partition coefficient; WW, wastewater; Manuf, manufacturing; \%, percent; >, greater than; CP, combustion product; USEPA, U.S. Environmental Protection Agency; UV, ultraviolet; --, no data]

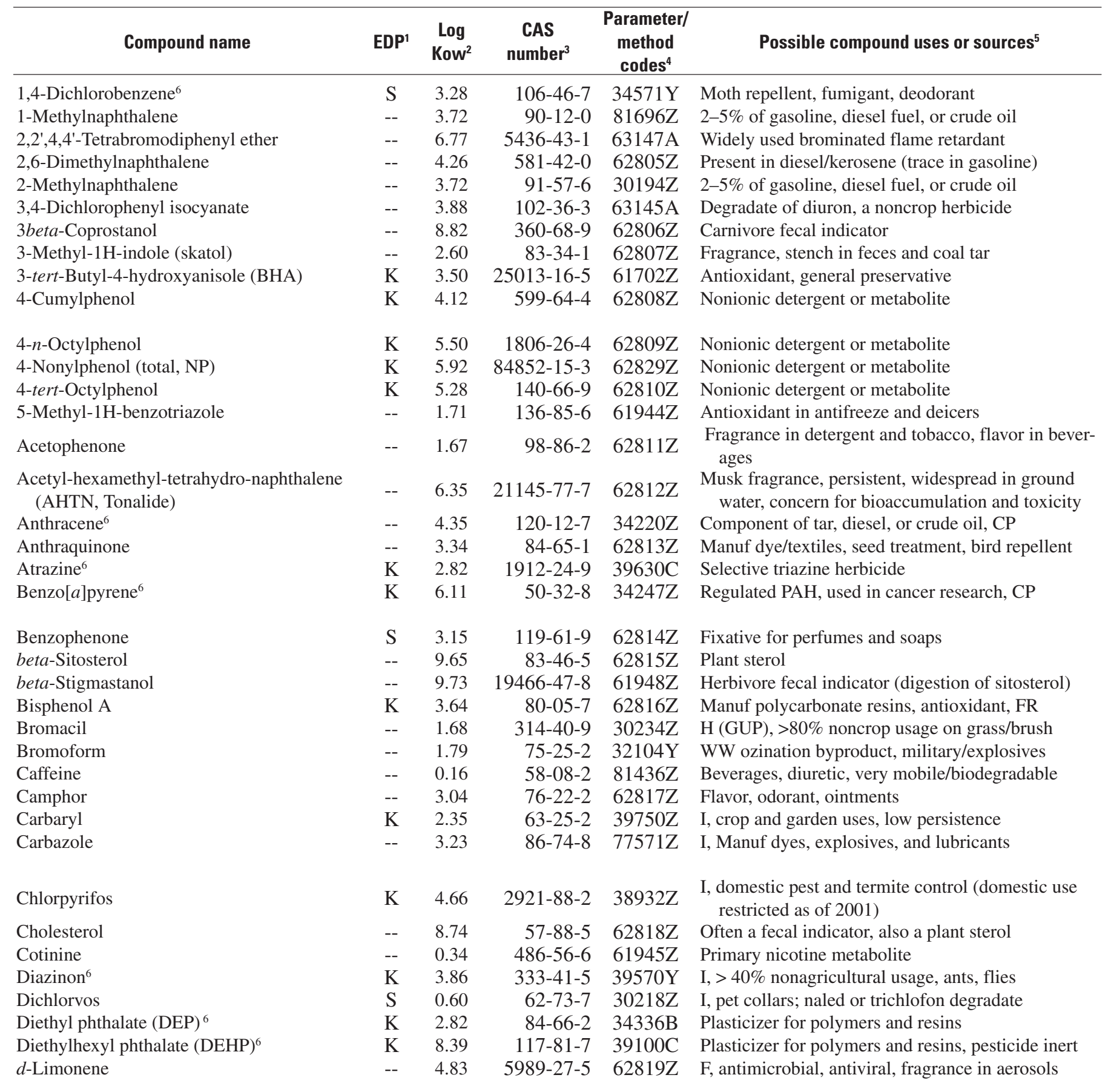


Table 1. Wastewater method compound names, endocrine-disrupting potential, log Kow, parameter/method codes, and possible compound uses-Continued.

[EDP, endocrine-disrupting potential; K, known; S, suspected; CAS, Chemical Abstract Service; F, fungicide; H, herbicide; I, insecticide; GUP, general use pesticide; FR, flame retardant; PAH, polycyclic aromatic hydrocarbon; Kow, octanol-water partition coefficient; WW, wastewater; Manuf, manufacturing; \%, percent; >, greater than; CP, combustion product; USEPA, U.S. Environmental Protection Agency; UV, ultraviolet; --, no data]

\begin{tabular}{|c|c|c|c|c|c|}
\hline Compound name & EDP1 & $\begin{array}{l}\log \\
\text { Kow }^{2}\end{array}$ & $\begin{array}{c}\text { CAS } \\
\text { number }^{3}\end{array}$ & $\begin{array}{c}\text { Parameter/ } \\
\text { method } \\
\text { codes }^{4}\end{array}$ & Possible compound uses or sources ${ }^{5}$ \\
\hline Fluoranthene $^{6}$ & -- & 4.93 & $206-44-0$ & $34376 Z$ & $\begin{array}{l}\text { Component of coal tar and asphalt (only traces in } \\
\text { gasoline or diesel fuel), CP }\end{array}$ \\
\hline $\begin{array}{l}\text { Hexahydrohexamethyl-cyclopenta- } \\
\text { benzopyran (HHCB, Galaxolide) }\end{array}$ & -- & 6.26 & $1222-05-5$ & $62823 Z$ & $\begin{array}{l}\text { Musk fragrance, persistent, widespread in ground } \\
\text { water, concern for bioaccumulation and toxicity }\end{array}$ \\
\hline Indole & -- & 2.05 & $120-72-9$ & $62824 Z$ & Pesticide inert ingredient, fragrance in coffee \\
\hline Isopropylbenzene (cumene) & -- & 3.45 & $98-82-8$ & $77223 \mathrm{Y}$ & Manuf phenol/acetone, fuels and paint thinner \\
\hline Isoquinoline & -- & 2.14 & $119-65-3$ & $62826 Z$ & Flavors and fragrances \\
\hline Menthol & -- & 3.38 & 89-78-1 & $62827 Z$ & Cigarettes, cough drops, liniment, mouthwash \\
\hline Metalaxyl & -- & 1.70 & $57837-19-1$ & $04254 Z$ & H, F (GUP), mildew, blight, pathogens, golf/turf \\
\hline Methyl salicylate & -- & 2.60 & 119-36-8 & $62828 Z$ & Liniment, food, beverage, UV-absorbing lotion \\
\hline Nonylphenol, diethoxy- (total, NPEO2) & $\mathrm{K}$ & -- & $26027-38-2$ & $61703 Z$ & Nonionic detergent \\
\hline Nonylphenol, monoethoxy- (total, NPEO1) & $\mathrm{K}$ & -- & 104-35-8 & $61704 \mathrm{~A}$ & Nonionic detergent \\
\hline Octylphenol, diethoxy-(OPEO2) & $\mathrm{K}$ & -- & $26636-32-8$ & $61705 Z$ & Nonionic detergent \\
\hline Octylphenol, monoethoxy-(OPEO1) & $\mathrm{K}$ & -- & $26636-32-8$ & $61706 Z$ & Nonionic detergent \\
\hline$p$-Cresol & -- & 2.06 & $106-44-5$ & $77146 Z$ & Wood preservative \\
\hline Pentachlorophenol $^{6}$ & $\mathrm{~S}$ & 4.74 & $87-86-5$ & $39032 Z$ & $\mathrm{H}, \mathrm{F}$, wood preservative, termite control \\
\hline Phenanthrene ${ }^{6}$ & -- & 4.35 & $85-01-8$ & $34461 Z$ & $\begin{array}{l}\text { Manuf explosives, component of tar, diesel fuel, } \\
\text { or crude oil, } \mathrm{CP}\end{array}$ \\
\hline Phenol $^{6}$ & -- & 1.51 & $108-95-2$ & $34694 Z$ & Disinfectant, Manuf several products, leachate \\
\hline Prometon $^{6}$ & -- & 3.57 & $1610-18-0$ & $39056 Z$ & H (noncrop only), applied prior to blacktop \\
\hline Triethyl citrate (ethyl citrate) & -- & 0.33 & $77-93-0$ & $62833 Z$ & Cosmetics, pharmaceuticals \\
\hline Triphenyl phosphate & -- & 4.70 & $115-86-6$ & $62834 Z$ & Plasticizer, resin, wax, finish, roofing paper, FR \\
\hline
\end{tabular}

${ }^{1}$ Colburn and others (2000), Our Stolen Future website (http://www.ourstolenfuture.org/Basics/chemlist.htm).

${ }^{2}$ Log Kow calculated using USEPA's exposure assessment tools and models (EPI-suite software, WSKOWWIN ${ }^{\mathrm{TM}}$ version 1.40; U.S. Environmental Protection Agency, 2005).

${ }^{3}$ CAS Registry Number ${ }^{\circledR}$ is a Registered Trademark of the American Chemical Society. CAS recommends the verification of the CASRNs through CAS Client Services. See www.cas.org

${ }^{4}$ Parameter codes define sample constituent variables linked to compound analytical results stored in the National Water Information System data base.

${ }^{5}$ ChemFinder Webserver (2006); National Toxicology Program (2006); National Institute of Standards and Technology (2006); Spectrum Laboratories, Inc. (2006); HealthCentral.com (2006); EXtension TOXicology NETwork (2006).

${ }^{6}$ Compound determined by at least one other whole-water method at the National Water Quality Laboratory. 
environmental problem similar to the PCBs (de Boer and others, 1998) because of their toxicity and extensive use in many common products. These compounds are present at low concentrations in the environment (nearly less than the detection capabilities of this method) because of their low water solubility. However, the most common PBDE detected in the environment (2,2', 4,4'-tetrabromodiphenyl ether) has been detected in a few samples using this method.

A complementary method to detect wastewater compounds in sediments and suspended particles using accelerated solvent extraction (ASE) also has been developed (Burkhardt and others, 2006). The ASE sediment method has been developed primarily to detect all the method compounds except 5-methyl-1H-benzotriazole, caffeine, cotinine, dichlorvos, and triethyl citrate (log Kow less than about 2, see table 1).

\section{Method Summary}

Whole-water samples are collected in 1-L amber glass pesticide bottles according to standard USGS sampling procedures for the determination of trace organic compounds (U.S. Geological Survey, variously dated) and shipped at $4^{\circ} \mathrm{C}$ to the NWQL. The whole-water samples (1-L) are immediately treated with the addition of $60 \pm 10 \mathrm{~g} \mathrm{NaCl}$ and stored at $4^{\circ} \mathrm{C}$. Samples are transferred to CLLE vessels before the expiration of the 2-week holding time and extracted with DCM at ambient $\mathrm{pH}$ for 3 hours and initially at $\mathrm{pH} 2$ for an additional 3 hours. Next, the DCM extract is evaporated by using a gentle stream of nitrogen to a final volume of $400 \mu \mathrm{L}$. The extracts are stored in a freezer at $\leq-10^{\circ} \mathrm{C}$ until compounds are determined by capillary-column GC/MS.

\section{Interferences}

Organic compounds that have gas chromatographic retention times and characteristic ions with a mass identical to those of the compounds of interest might interfere. There might be unknown compounds that interfere because of the complex nature of wastewater.

Sample-collection protocols and cleaning procedures for field equipment (U.S. Geological Survey, variously dated) must be followed to reduce the possibility of interferences and to minimize potential contamination. Many method compounds are widespread in the environment and have been detected in laboratory reagentwater-blank samples. For example, diethylhexyl phthalate might contribute to environmental contamination. Samples and collection equipment that are handled improperly also might become contaminated with soaps, caffeine, and fragrances. Precautions are necessary to avoid and minimize the potential for contamination during sample collection (see section 7.1) because some method compounds are contained in commonly used products.

\section{Apparatus and Instrumentation}

4.1 Continuous liquid-liquid extractors (custom made by Allen Scientific Glass, Inc. and not commercially available) include a condenser, a coarse frit at the head of the water sample for microdispersion of methylene chloride, and a 1-L extraction chamber to hold the sample (see fig. 1). A heating mantle is placed over a $25-\mathrm{mL}$ receiver to gently boil the methylene chloride solvent. The solvent vapor is condensed and returns to the frit to continuously extract the sample. During the CLLE process the extracted sample is concentrated in

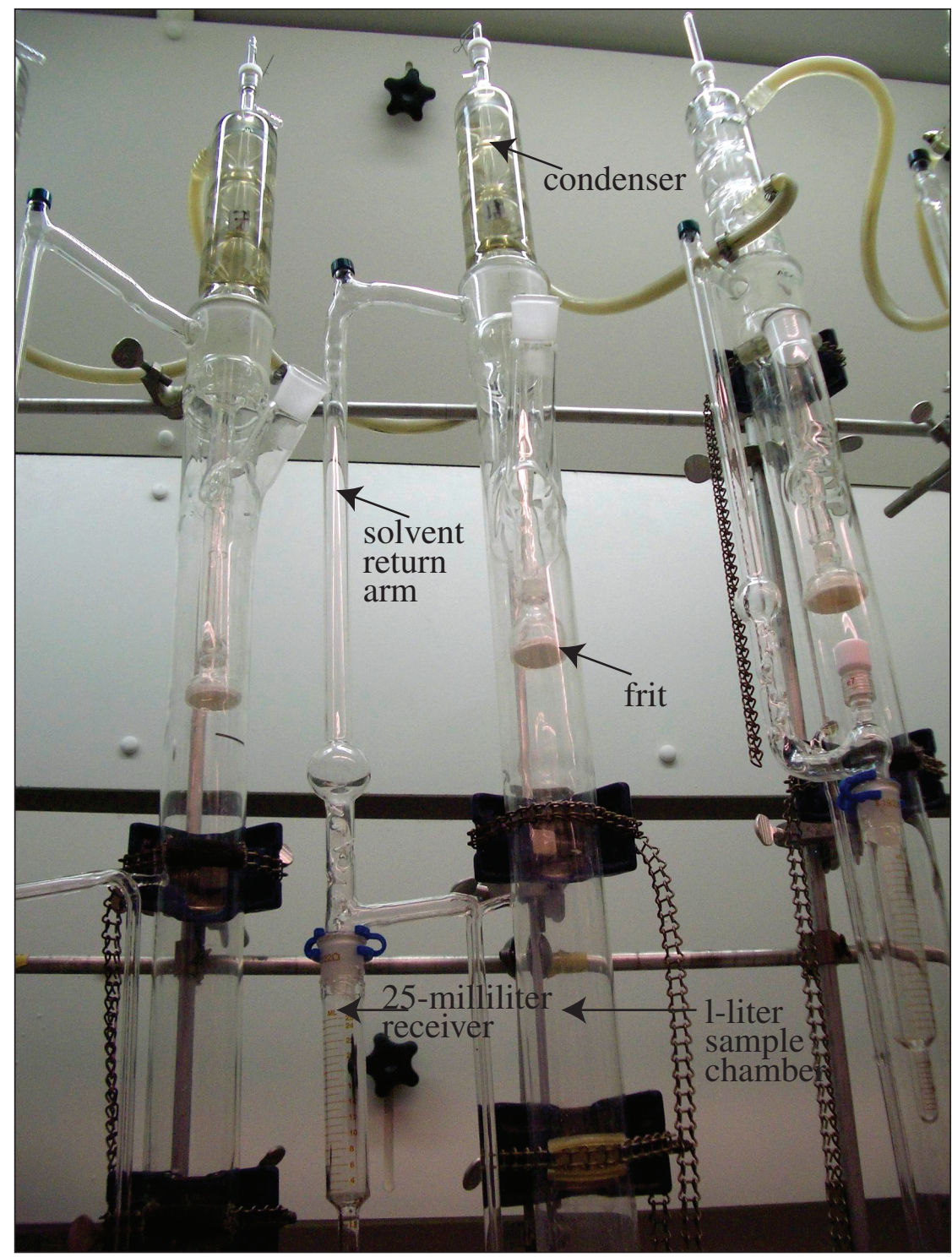

Figure 1. Continuous liquid-liquid extractors with solvent-dispersing frits mounted in a fume hood. 
the 25-mL receiver (see Section 7, Sample Preparation) for details.

4.2 Variac variable transformer; 0 to 140 volts or equivalent.

4.3 Heating mantle; tube or teardrop-shaped.

4.4 Carboy or equivalent waste container resistant to chlorinated solvents.

4.5 Kuderna-Danish receivers (concentrator tubes); $25-\mathrm{mL}$ graduated, Kontes part number 570081-2526 or equivalent.

4.6 Analytical balances, capable of accurately weighing 1,500 $\pm 1 \mathrm{~g}$ for samples and $50 \pm 0.01 \mathrm{mg}$ for standard preparation.

4.7 Nitrogen evaporative concentrator; Organomation $\mathrm{N}$-Evap or equivalent.

4.8 Micropipettes; 50-, 100-, and 200- $\mu \mathrm{L}$ fixed-volume and variable-volume micropipettes with disposable glass bores; VWR Scientific or equivalent.

4.9 Glass syringes; 10-, 50-, 100-, 250-, and 500- $\mu \mathrm{L}$ volume.

4.10 Funnels; stainless steel, baked 8 hours at $450^{\circ} \mathrm{C}$.

4.11 Fused-silica capillary column; any column that provides adequate resolution, capacity, accuracy, and precision. A $30-\mathrm{m}$ by $0.25-\mathrm{mm}$ inside diameter fused-silica capillary column coated with a $0.50-\mu \mathrm{m}$ bonded film of 5-percent polyphenylmethylsilicone; J\&W Scientific DB-5MS column or equivalent.

4.12 GC/MS bench-top system; Agilent Technologies, Model 5973 or equivalent.

4.12.1 Recommended GC conditions; oven, $40^{\circ} \mathrm{C}$ (hold 3 minutes), then ramp at $4^{\circ} \mathrm{C} / \mathrm{min}$ to $100^{\circ} \mathrm{C}$, and $9^{\circ} \mathrm{C} / \mathrm{min}$ to $320^{\circ} \mathrm{C}$; injection port, $290^{\circ} \mathrm{C}$ with electronic pressure control set for a constant flow of helium carrier gas of $1 \mathrm{~mL} / \mathrm{min}$; injection volume, $2 \mu \mathrm{L}$, splitless injection.

4.12.2 Recommended MS conditions; source, $200^{\circ} \mathrm{C}$; quadrupole analyzer, $100^{\circ} \mathrm{C}$; interface, held at $250^{\circ} \mathrm{C}$ and programmed at $9^{\circ} \mathrm{C} / \mathrm{min}$ to $290^{\circ} \mathrm{C}$ when the oven temperature surpasses $250^{\circ} \mathrm{C}$; electron-impact ionization mode (70 electron volts), full-scan mode from 45 to 450 atomic mass units in 0.5 second.

\section{Reagents and Consumable Materials}

5.1 Carrier gas; helium ( 99.999 percent).

5.2 Nitrogen gas; for evaporation, ultrapure.
5.3 Sodium chloride; reagent grade, baked 8 hours at $450^{\circ} \mathrm{C}$, VWR or equivalent.

5.4 Glass bottles; amber, 1,000-mL, 33-mm neck, baked at $450^{\circ} \mathrm{C}$ for 2 hours, fitted with Teflon-lined screw caps; NWQL GCC or equivalent.

5.5 Solvents; isopropyl alcohol and acetone, B\&J Brand, pesticide grade or equivalent.

5.5.1 Dichloromethane, $20-\mathrm{L}$ pressurized solvent keg, B\&J, catalog number NS300-20.

5.6 Organic contaminant-free water; Solution 2000 reagent water; prepared by Solution 2000 purification system or equivalent.

5.7 Pasteur pipettes; disposable, baked 8 hours at $450^{\circ} \mathrm{C}$.

5.8 Vial; 2-mL, amber glass, with Teflon-lined screw caps, Supelco Inc. or equivalent.

5.9 Boiling chips; four-mesh granule sizes, baked 8 hours at $450^{\circ} \mathrm{C}$.

5.10 Sulfuric acid; reagent-grade, 25 percent, diluted in Solution 2000 water.

\section{Standards}

6.1 Stock standard solutions at $10,000 \mathrm{ng} / \mathrm{\mu L}$. Obtain method compounds and surrogate compounds at greater than 99percent purity from commercial vendors. Prepare stock standard solutions of each individual compound at about 10,000 $\mathrm{ng} / \mathrm{\mu L}(10 \mathrm{mg} / \mathrm{mL})$ by accurately weighing, to the nearest $0.002 \mathrm{mg}, 20 \mathrm{mg}$ of the neat material in a $2-\mathrm{mL}$ volumetric flask and dilute to volume with DCM. Three of the method compounds (4-NP, OPEO1, and OPEO2) are only available in technical mixtures. For the technical grade nonylphenol (NP) mixture (1-NP and 4-NP) and the Igepal 210 (Dupont, Inc.) mixture (OPEO1 and OPEO2), the final concentration of the stock standard solutions is calculated on the basis of the percentage contribution of each compound to the total ion chromatograms of the technical mixtures. These compounds are identified in the total ion chromatogram by referring to their characteristic ions and relative retention times (see table 2 in Section 10, Instrument Calibration).

The contribution of the 4-nonylphenols (total) in the NP technical mixture is determined by manually integrating the sum of the peaks within the expected retention time window (fig. 2) for the quanitation ion $(\mathrm{m} / \mathrm{z} 135$, see table 2 , section 10). Also, note how the confirmation ion profiles $(\mathrm{m} / \mathrm{z} 220$ and 107) must coincide in a similar pattern with ion 135. The ortho-NPs elute prior to the 4-NPs and are not determined in this method because their contribution to the 


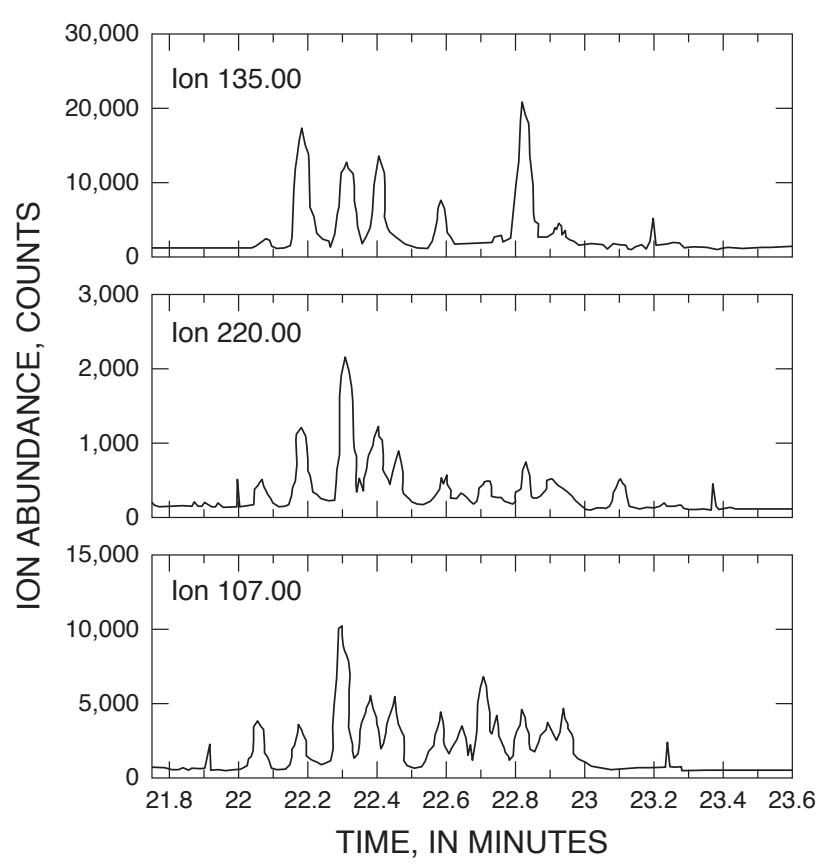

Figure 2. Manual integration of the extracted ion profile for the quantitation ion (mass-to-charge ratio 135) of 4-nonylphenol from the 2- nanogram-per-microliter calibration solution for the wastewater method (from Zaugg and others, 2002).

total ion chromatogram is minimal (less than 7 percent). In general, it is desirable, for the purposes of making dilutions of the mixed standard solution, to prepare a stock standard solution of the 4-NP isomers (total), which is 16 times the concentration of the stock standard solutions of the singlecomponent compounds in the method. To prepare this stock standard solution, calculate the necessary amount of the technical mixture needed (about $180 \mathrm{mg} / \mathrm{mL}$ ).

The Igepal 210 technical mixture is mainly composed of single components of OPEO1 and OPEO2 in a ratio of about 10 to 1 , respectively. A convenient concentration of a stock standard solution for OPEO1 is prepared at 4 times the concentration of the single-component compounds, or $40 \mathrm{mg} / \mathrm{mL}$. This concentration also provides enough material for calibrating OPEO2 (about $4 \mathrm{mg} / \mathrm{mL}$ ) from the same stock standard solution. The preparation of the OPEO1 and OPEO2 stock standard solution, thus, generally requires about $45 \mathrm{mg} / \mathrm{mL}$ (as calculated) of the Igepal 210 technical mixture. Reference standards for the NPEO1s and NPEO2s were obtained as separate mixtures from the Aldrich chemical company by a custom synthesis requested by the U.S. Environmental Protection Agency.

6.2 Intermediate method compound standard solution at 100 $n g / \mu L$. Prepare a mixed stock standard solution that contains each intermediate method compound standard solution at 100 $\mathrm{ng} / \mu \mathrm{L}$ (not including surrogate compounds). Use an adjustable $100-\mu \mathrm{L}$ dispenser and a $10-\mathrm{mL}$ volumetric flask to prepare this intermediate method compound standard solution and dilute with DCM.
6.3 Surrogate spiking solution at $20 \mathrm{ng} / \mu \mathrm{L}$. Combine $100 \mu \mathrm{L}$ of stock standard solution at $10,000 \mathrm{ng} / \mu \mathrm{L}$ for each surrogate compound listed in table 2 (see Section 10, Instrument Calibration) in a $50-\mathrm{mL}$ volumetric flask and dilute with isopropyl alcohol. Add $100 \mu \mathrm{L}$ of the $20-\mathrm{ng} / \mu \mathrm{L}$ intermediate method compound standard solution to a 1-L sample to obtain a surrogate spiking solution of $2.0 \mu \mathrm{g} / \mathrm{L}$. A surrogate concentration of $5.0 \mathrm{ng} / \mu \mathrm{L}$ is expected in a $400-\mu \mathrm{L}$ extract if 100 percent of the surrogate is recovered through the sample-preparation procedure.

6.4 Mixed surrogate and method compounds solution at 50 $n g / \mu L$. Add $5.0 \mathrm{~mL}$ of the $100-\mathrm{ng} / \mu \mathrm{L}$ intermediate method compound standard solution (see section 6.2) to a $10-\mathrm{mL}$ flask. Add $50 \mu \mathrm{L}$ of each of the stock standard solutions and surrogate standard solutions at 10,000 $\mathrm{ng} / \mu \mathrm{L}$ (see section 6.1) and dilute with DCM. This mixture is used to prepare the calibration solutions (section 6.7).

6.5 Spike solution at $20 \mathrm{ng} / \mathrm{\mu L}$. Dilute $2.0 \mathrm{~mL}$ of the intermediate method compound standard solution at $100 \mathrm{ng} / \mu \mathrm{L}$ (see section 6.2) in a 10-mL volumetric flask with isopropyl alcohol. Add $100 \mu \mathrm{L}$ to a 1-L sample to obtain a compound concentration of $2.0 \mu \mathrm{g} / \mathrm{L}$. A concentration of $5.0 \mathrm{ng} / \mu \mathrm{L}$ is expected in a $400-\mu \mathrm{L}$ extract if 100 percent of the spike is recovered.

6.6 PAH procedural internal standard solution at $100 \mathrm{ng} / \mu \mathrm{L}$. The internal standards (see table 2, Section 10, Instrument Calibration) are obtained from Supelco (or equivalent) in a mixture at $2,000 \mathrm{ng} / \mu \mathrm{L}$. Add $2.5 \mathrm{~mL}$ of this mixture to a 50 $\mathrm{mL}$ flask and dilute with DCM. Note that $20 \mu \mathrm{L}$ of the polycyclic aromatic hydrocarbon $(\mathrm{PAH})$ procedural internal standard solution at $100 \mathrm{ng} / \mu \mathrm{L}$ in a $400-\mu \mathrm{L}$ extract is equivalent to a concentration of $5 \mathrm{ng} / \mu \mathrm{L}$.

6.7 Calibration solutions. Prepare a series of calibration solutions in DCM that contain all of the method and surrogate compounds at concentrations for most compounds ranging from 0.05 to $40.0 \mathrm{ng} / \mu \mathrm{L}(0.05,0.1,0.2,0.5,1.0,2.0,5.0$, $10,20,40 \mathrm{ng} / \mu \mathrm{L})$. The concentration of single-component compounds in the calibration mixture that respond poorly by GC/MS (bromacil, cholesterol, cotinine, 3beta-coprostanol, beta-stigmastanol, beta-stitosterol, 5-methyl-1H-benzotriazole, and pentachlorophenol) is 4 times that of the other singlecomponent compounds. The concentration of the multicomponent compounds in the calibration mixture, NP (total), NPEO1 (total), and NPEO2 (total), is 18 times, 16 times, and 16 times, respectively, that of the single-component compounds in the calibration mixture. The concentration of the PAH procedural internal standard solution in the calibration solutions is kept constant at $5.0 \mathrm{ng} / \mu \mathrm{L}$. Prepare these calibration solutions by adding the appropriate volumes of the mixed surrogate and method compounds solution at $50 \mathrm{ng} / \mu \mathrm{L}$ and the $\mathrm{PAH}$ procedural internal standard solution at $100 \mathrm{ng} / \mu \mathrm{L}$ into volumetric flasks and diluting to volume with DCM. 


\section{Sample Preparation}

7.1 Collect whole-water samples in 1-L amber glass pesticide bottles (NWQL type GCC) before shipping at $4^{\circ} \mathrm{C}$ to the NWQL, preferably by express overnight mail. Fill the bottle to the neck, and leave sufficient headspace (about $30-40$ $\mathrm{mL}$ ) for the addition of $60 \mathrm{~g} \mathrm{NaCl}$ upon arrival at the NWQL. Field-sampling procedures need to follow those typically used to collect samples for trace organic compound determinations (Ward and Harr, 1990; Wilde, April 2004; Wilde and others, April 2004; U.S. Geological Survey, variously dated) with specific instructions for the collection of wastewater compounds (Wilde and others, section 5.6.1.F, April 2004).

CAUTION: Some of the compounds that are determined by this method are found in commonly used products, such as coffee, tea, cola, soap, and insecticide repellent. Project personnel need to be careful to avoid potential contamination of samples from such sources by avoiding consumption or contact with these materials immediately prior to and during sampling procedures. Limit or avoid contact with any fragranced materials, including colognes, scented-detergents, shampoos, and conditioners. If samples are suspected of containing untreated sewage or biohazards, special shipping, handling, and processing requirements need to be followed (U.S. Geological Survey, variously dated) prior to shipping. Clean the outside of the bottle thoroughly with isopropyl alcohol and secure the lid tightly before wrapping in four high-capacity $3 \mathrm{M}$ sorbent pads (Lab Safety and Supply, Janesville, Wis., catalog number 2BD26577). Finally, enclose the wrapped bottle in three resealable plastic bags (two bags are necessary and one bag is precautionary).

The probability of sample contamination with compounds determined by this method is higher than for other NWQL methods. For this reason, routinely prepare field blanks for analysis by using EMD Chemicals, Inc. Omni Solv® water or NWQL blank water (OneStop Shopping number N1570) to monitor for potential sample contamination.

7.2 When the sample is received, if the sample bottle has less than about $30 \mathrm{~mL}$ of headspace, discard a minimum amount of water to provide enough headspace for later addition of $60 \mathrm{~g} \mathrm{NaCl}$. Weigh the sample plus bottle and record the gross weight $( \pm 1 \mathrm{~g})$. After the gross weight has been recorded, add $60 \pm 10 \mathrm{~g} \mathrm{NaCl}$ (baked) to make the sample about 1 molar $\mathrm{NaCl}$. Mix well to ensure the $\mathrm{NaCl}$ has dissolved completely. Store samples in a refrigerator at $4^{\circ} \mathrm{C}$ for up to 14 days from the time of sample collection.

NOTE: Addition of $\mathrm{NaCl}$ to samples increases the ionic strength and improves recovery of polar compounds during extraction.

7.3 The CLLE vessels must be mounted in a fume hood (see fig. 1) because of the organic solvents that are used in this method. Prior to loading samples in the CLLE vessels (usually the day before extraction), rinse each vessel, stopper, and receiver (first with reagent water, second with acetone, and third with DCM). Close the Teflon stopcock at the base of the CLLE vessels. Place two to five boiling chips in the bottom of each $25-\mathrm{mL}$ receiver and attach firmly to the extractor with a connector clip.

7.4 Prepare two additional 1-L bottles for each set of up to 18 samples for the laboratory reagent set blank and the reagent set spike containing about $900 \mathrm{~mL}$ of Solution 2000 water and $60 \pm 10 \mathrm{~g}$ of $\mathrm{NaCl}$. Add $100 \mu \mathrm{L}$ of surrogate spiking solution (20 ng/ $\mu \mathrm{L}$; see section 6.3) to each sample, including the set blank and spike. Add $100 \mu \mathrm{L}$ of primary fortification spike solution (20 ng/ $\mu \mathrm{L}$; see section 6.5$)$ into the reagent water spike sample. (This step results in a concentration of $2.0 \mu \mathrm{g} / \mathrm{L}$ for the fortified spike compounds and surrogate compounds in a 1-L sample.) Cap each sample bottle and shake well to mix. Ensure all the $\mathrm{NaCl}$ has dissolved.

7.5 Add $50 \mathrm{~mL}$ of DCM to each CLLE vessel using the pressurized solvent keg. Shake each sample and carefully transfer into a CLLE vessel through the side access arm. Use a clean stainless-steel funnel to facilitate this transfer. Transfer the water and any particulate matter to the CLLE vessel. Rinse the sample bottle well with about 10 to $15 \mathrm{~mL}$ of Solution 2000 water and pour the rinse into the CLLE vessel. Then, rinse the sample bottle with about 10 to $15 \mathrm{~mL} \mathrm{DCM}$, and swirl or rotate the bottle to ensure the entire inside glass surface has contact with solvent, and pour the solvent rinse into the CLLE vessel. Rinse with the solvent a second time, following the same procedure. Finally, rinse the sample bottle with Solution 2000 reagent water to remove residual DCM and transfer to the CLLE vessel.

NOTE: Thoroughly rinsing sample bottles is important because more than 30 percent of some hydrophobic compounds (particularly PAHs, sterols, and organochlorine compounds) might adhere to glass walls.

7.6 With the frit assembly raised out of the way, add Solution 2000 water to the extractor until DCM just begins to drip from the CLLE vessel solvent return arm into the 25-mL receiver. Lower the frit assembly until the bottom of the frit just touches the surface of the water.

7.7 Add DCM with a Teflon ${ }^{\circledR}$ squirt bottle (or preferably directly from a pressurized solvent dispensing drum) into the spout at the top of the condenser until the reservoir above the frit is filled. DCM will begin to disperse from the microdroplet dispersing frit. Continue adding DCM until there is about 15 $\mathrm{mL}$ of DCM in the receiver.

NOTE: Sometimes the frit will need to be rattled to remove trapped air pockets and start DCM "raining." 
7.8 Turn on the water to the condensers and close the side access arm with a no. 22 glass stopper. Hook the heating mantle onto the receiver. Turn on the Variac voltage controllers and set at 70 volts. Watch the receiver to ensure that the DCM is boiling vigorously and extract for 3 hours at ambient $\mathrm{pH}$.

NOTE: Ambient $\mathrm{pH}$ is used because recoveries of a few compounds subject to hydrolysis (particularly phthalate esters) are somewhat better than at basic $\mathrm{pH}$.

After 3 hours, reduce the $\mathrm{pH}$ with the addition of $3 \mathrm{~mL} \mathrm{H}_{2} \mathrm{SO}_{4}$ (25 percent, $\mathrm{pH}$ 2) through the side arm of the CLLE vessel.

NOTE: Check the volume of DCM in the receiver every 15 to 30 minutes to maintain a volume of about 15 to $20 \mathrm{~mL}$. Add DCM through the spout at the top of the condenser to make this volume adjustment during the first 3 hours of extraction. After 3 hours, if the volume of DCM in the CLLE vessel is greater than $50 \mathrm{~mL}$, add Solution 2000 reagent water through the side access arm to make this volume adjustment. If at any time the volume of DCM in the CLLE vessel is less than 50 $\mathrm{mL}$, add DCM through the spout at the top of the condenser.

7.9 After 6 hours of sample extraction, drain the CLLE vessel into a designated waste carboy. This step also will cut off the return of DCM to the receiver. Continue to boil the DCM in the receivers until the level reaches 4 to $8 \mathrm{~mL}$. Remove the heating mantle and allow the receivers to cool before removing them. Turn off the Variac heater and the water to the condensers.

NOTE: This boiling concentration step follows quickly and requires constant monitoring to remove the heating mantle when the DCM level is between 4 and $8 \mathrm{~mL}$. At no time should the solvent be allowed to boil dry because of volatile compound losses.

7.10 After the sample has drained from the CLLE vessel, rinse all CLLE surfaces immediately with copious amounts of Solution 2000 reagent water to ensure all surfaces are thoroughly wetted. Make sure all suspended material has been rinsed out of the CLLE vessel. While the walls of the CLLE vessel are still wet, rinse with $60 \mathrm{~mL}$ of acetone followed by $60 \mathrm{~mL}$ of DCM.

NOTE: The NWQL needs to be notified if a sample might contain raw sewage (section 8.1). If this is the case, double or triple the amount of water and solvents in the rinse to ensure that the CLLE vessel is clean.

7.11 Record the empty sample bottle weight $( \pm 1 \mathrm{~g})$ to obtain the weight of the extracted sample.

7.12 Add $20 \mu \mathrm{L}$ of the PAH procedural internal standard solution (100 ng/ $\mu \mathrm{L}$; see section 6.6) to each sample extract by using a $1.0-\mathrm{mL}$ stepper syringe. Prepare the 24-position $\mathrm{N}$-Evap nitrogen evaporator by attaching cleaned and burned stainless-steel needles in each position. Set the nitrogen flow rate to about $3.5 \mathrm{~L} / \mathrm{min}$ and adjust the flow visually so that a slightly detectable ripple can be seen on the surface of the extracts. Remove the extracts when the final volume is $400 \mu \mathrm{L}$. To maintain a more consistent flow rate for remaining extracts, leave the needles attached to the N-Evap with the flow of nitrogen remaining unaltered. Concentrate the DCM extract at ambient temperature and periodically check the extracts. Do not allow the extract to evaporate to less than $300 \mu \mathrm{L}$.

7.13 Vortex the extract so that the solvent rinses the glass walls of the receiver. Then use a baked, disposable glass Pasteur pipette to transfer concentrated $(400 \mu \mathrm{L})$ extracts to appropriately labeled, screw-cap GC vials that contain $400-\mu \mathrm{L}$ glass inserts. Ensure that the screw cap forms a tight seal. Store extracts in a freezer at $\leq-10^{\circ} \mathrm{C}$ for up to 45 days prior to GC/MS analysis.

\section{Safety Precautions and Waste Disposal}

8.1 Sample Handling. All field and laboratory staff who handle samples are required to have tetanus/diphtheria, hepatitis A, and hepatitis B immunizations. Nitrile or latex gloves, protective glasses, and laboratory coats also are necessary. If samples might contain untreated sewage or biohazards, field personnel are instructed to clean the outside surfaces of the bottle thoroughly with isopropyl alcohol and water to prepare for shipment to the NWQL according to the USGS field manual (U.S. Geological Survey, variously dated). It is necessary for all NWQL personnel to wear disposable gloves when handling sample bottles. Change gloves frequently.

NOTE: As a warning to NWQL personnel, the accompanying analytical services request (ASR) form for samples that possibly contain untreated sewage or biohazards must clearly indicate in capital letters in the hazards comment field: "SAMPLE MIGHT CONTAIN SEWAGE. HANDLE WITH CAUTION."

8.2 Conduct the CLLE extraction and DCM concentration in a fume hood. Eye protection, gloves, and protective clothing must be worn in the laboratory area and when handling reagents or solvents. Avoid contact with DCM because typical laboratory disposable, nitrile gloves do not provide adequate protection from DCM.

8.3 The sample waste stream produced during sample preparation is about 1 molar $\mathrm{NaCl}$ and $\mathrm{pH} 2$. It is collected in carboys, and must be disposed of according to local regulations. Solvent and DCM used to clean or rinse glassware, SPE cartridges, or equipment also must be disposed of in the appropriate waste containers. All bags, bottles, and consumable items associated with sample processing must be segregated and disposed of properly. 


\section{Gas chromatograph/mass spectrometer performance}

The performance of the analytical instrumentation is checked at least every 24 hours to ensure that it meets qualityassurance guidelines of sensitivity and accuracy necessary to obtain reproducible sample results.

\subsection{Gas chromatograph performance evaluation}

Gas chromatograph performance is indicated by peak shape, compound resolution, and verification of selectedcompound response factors of a low-level standard. An example of the separation and peak shape for the complex mixture of NP compounds is shown in the selected ion chromatogram (fig. 2) of a $2.0-\mathrm{ng} / \mu \mathrm{L}$ calibration solution. If peak shape and resolution deteriorates (indicated by a loss in the number of resolved NP isomers, fig. 2) or if compounds fail to meet the calibration criteria (see Section 10, Instrument Calibration), change the injection port liner or maintain the capillary column to bring the gas chromatograph into compliance. About $0.6 \mathrm{~m}$ (one column loop) of the capillary-column inlet end often can be removed to restore GC performance. Specifically, a loss in response greater than 30 percent for cholesterol indicates the need for replacement of the GC inlet liner, or maintenance of the column, or both. Instrument maintenance requires recalibrating the method compounds and reanalysis of samples.

\subsection{Mass spectrometer performance evaluation}

9.2.1 Check for air (m/z 28 and 32) and water (m/z 18) leaks in the GC/MS prior to analysis. If air leaks are detected, as indicated by the presence of nitrogen $(\mathrm{m} / \mathrm{z} 28)$ greater than 10 percent of the $\mathrm{m} / \mathrm{z} 69$ peak area of the perfluorotributylamine tuning compound, then locate and fix the leaks. Also, check the instrument before each sequence of analyses to ensure that mass spectrometer performance is in accordance with the perfluorotributylamine tuning criteria outlined below (section 9.2.2). In addition, adjust the mass spectrometer response (also outlined in section 9.2.2) to ensure that the established interim reporting level (IRL) for each selected compound can be achieved.

9.2.2 Check the mass spectrometer tune prior to sample analysis.

NOTE: The following guidance applies to the Agilent Technologies model 5973 GC/MS system. Other GC/MS systems might require different adjustments to achieve the method performance criteria.

The mass axis and MS peak-width adjustment characteristics must be set to give \pm 0.15 -atomic mass unit accuracy at masses 69,219 , and 502 in the spectrum of perfluorotributylamine. Adjust the electron multiplier voltage to achieve about $1,000,000$ counts for the mass 69 ion. This setting generally will provide sufficient signal to meet detection requirements for method compounds at method detection limit (MDL) concentrations in samples, provided that the GC is performing properly. Manually adjust the resolution so that $\mathrm{m} / \mathrm{z}$ ion 69 has 100-percent abundance, mass 219 ion is $40 \pm 20$ percent, and mass 502 is $3 \pm 2$-percent relative abundance. Check mass assignments to ensure accuracy to \pm 0.15 atomic mass unit. Adjust peak widths measured at half height for ions 69, 219 , and 502 so that peak widths range from about 0.5 to 0.65 atomic mass unit. Adjustment of tune settings normally will require recalibrating the method compounds.

\section{Instrument calibration}

10.1 Inject $2 \mu \mathrm{L}$ of each calibration solution into the GC/MS and acquire data by using the previously described GC/MS conditions. Enter the calibration concentration levels, compound names, quantitation ion, confirmation ions, and approximate retention times listed in table 2 into the data-processing method. Use the GC/MS data-processing software to calculate the relative retention time (RRT) and relative response factor (RRF) for each compound and surrogate in relation to the designated internal standard reference compound (table 2) in the calibration solution. A calibration curve is calculated by the data-processing software for each compound. A linear calibration curve is suggested for most of the method compounds; however, other curve-fitting routines (quadratic curves and power curves) might be used for polar compounds. The same calibration curve type that demonstrates the "best fit" to the data for each compound must always be used in the method. Typical equations used to calculate calibration curves for this method are similar to other NWQL methods (Sandstrom and others, 2001).

10.2 Prior to the analysis of each sample set and every 10 samples thereafter during a series of analyses, analyze and evaluate a calibration solution (or solutions) that contain all of the method compounds to ensure that GC/MS performance is in compliance with established performance criteria (see section 9.2). The calculated concentration of method compounds in the continuing calibration verification solutions (CCVs), using the initial calibration curve, must be within \pm 25 percent of the expected concentration before analysis of environmental samples.

10.3 The multicomponent compounds (4-NPs, NPEO1, and NPEO2 mixtures each composed of 10 to 20 discernible isomers) are calibrated by manually integrating the area of their respective quantitation ion peaks that are present in the expected retention time window range (table 2). This approach was used for determining the concentration of compounds when preparing stock standard solutions (section 6.1, fig. 2) 
Table 2. Wastewater method compound retention time, quantitation ion, confirmation ions, surrogate compounds, and internal standard reference compound.

[Compounds are listed in order of retention time. min, minutes; m/z, mass-to-charge ratio; IS, internal standard; --, not used]

\begin{tabular}{|c|c|c|c|c|c|}
\hline Compound name & $\begin{array}{l}\text { Retention } \\
\text { time (min) } \\
\end{array}$ & $\begin{array}{c}\text { Quantitation } \\
\text { ion }(\mathrm{m} / \mathrm{z})\end{array}$ & $\begin{array}{c}\text { Confirmation } \\
\text { ion }(\mathrm{m} / \mathrm{z}) \\
\end{array}$ & $\begin{array}{c}\text { Confirmation } \\
\text { ion }(\mathrm{m} / \mathrm{z})\end{array}$ & $\begin{array}{c}\text { Internal standard } \\
\text { reference }\end{array}$ \\
\hline Tetrachloroethylene & 7.021 & 164 & 166 & 131 & IS 1 \\
\hline Bromoform & 10.233 & 173 & 171 & 175 & IS1 \\
\hline Isopropylbenzene (cumene) & 11.507 & 105 & 120 & -- & IS1 \\
\hline Phenol & 13.651 & 94 & 66 & 65 & IS 1 \\
\hline 1,4-Dichlorobenzene & 15.212 & 146 & 148 & 111 & IS1 \\
\hline d-Limonene & 15.819 & 93 & 136 & 121 & IS1 \\
\hline Acetophenone & 17.234 & 105 & 120 & 77 & IS1 \\
\hline p-Cresol & 17.460 & 107 & 108 & 77 & IS1 \\
\hline Isophorone & 19.298 & 82 & 138 & -- & IS2 \\
\hline Camphor & 20.135 & 90 & 105 & 152 & IS2 \\
\hline Isoborneol & 20.582 & 95 & 136 & 140 & IS2 \\
\hline Menthol & 20.921 & 95 & 123 & 138 & IS2 \\
\hline Naphthalene & 21.123 & 128 & 127 & 102 & IS2 \\
\hline Methyl salicylate & 21.269 & 120 & 152 & 92 & IS2 \\
\hline Dichlorvos & 22.374 & 109 & 85 & 220 & IS2 \\
\hline Isoquinoline & 22.834 & 129 & 102 & -- & IS2 \\
\hline Indole & 23.418 & 117 & 89 & -- & IS2 \\
\hline 2-Methylnaphthalene & 23.568 & 142 & 141 & 115 & IS3 \\
\hline 3,4-Dichlorophenyl isocyanate & 23.639 & 187 & 189 & 124 & IS3 \\
\hline 1-Methylnaphthalene & 23.869 & 142 & 141 & 115 & IS3 \\
\hline 3-Methyl-1H-indole (skatol) & 25.120 & 130 & 131 & -- & IS3 \\
\hline 2,6-Dimethylnaphthalene & 25.519 & 156 & 141 & -- & IS3 \\
\hline 3-tert-Butyl-4-hydroxyanisole (BHA) & 26.606 & 180 & 165 & 137 & IS3 \\
\hline 5-Methyl-1H-benzotriazole & 27.918 & 103 & 104 & 77 & IS3 \\
\hline N,N-Diethyl-meta-toluamide (DEET) & 27.983 & 119 & 190 & 91 & IS3 \\
\hline Diethyl phthalate & 28.064 & 149 & 177 & -- & IS3 \\
\hline 4-tert-Octylphenol & 28.320 & 135 & 206 & 107 & IS3 \\
\hline Benzophenone & 28.806 & 182 & 105 & 77 & IS3 \\
\hline Tributyl phosphate & 28.830 & 99 & 155 & 211 & IS3 \\
\hline Triethyl citrate (ethyl citrate) & 28.914 & 157 & 115 & 203 & IS4 \\
\hline
\end{tabular}




\section{Determination of Wastewater Compounds in Whole Water}

Table 2. Wastewater method compound retention time, quantitation ion, confirmation ions, surrogate compounds, and internal standard reference compound.-Continued

[Compounds are listed in order of retention time. min, minutes; m/z, mass-to-charge ratio; IS, internal standard; --, not used]

\begin{tabular}{|c|c|c|c|c|c|}
\hline Compound name & $\begin{array}{l}\text { Retention } \\
\text { time (min) }\end{array}$ & $\begin{array}{c}\text { Quantitation } \\
\text { ion }(\mathrm{m} / \mathrm{z})\end{array}$ & $\begin{array}{c}\text { Confirmation } \\
\text { ion }(\mathrm{m} / \mathrm{z})\end{array}$ & $\begin{array}{c}\text { Confirmation } \\
\text { ion }(\mathrm{m} / \mathrm{z})\end{array}$ & $\begin{array}{l}\text { Internal stan- } \\
\text { dard reference }\end{array}$ \\
\hline Cotinine & 29.761 & 98 & 176 & 147 & IS4 \\
\hline 4-Nonylphenol (total) & $29.7-30.6$ & 135 & 220 & 107 & IS4 \\
\hline Prometon & 30.099 & 210 & 225 & 168 & IS4 \\
\hline Atrazine & 30.218 & 200 & 215 & 202 & IS4 \\
\hline Tri(2-chloroethyl) phosphate & 30.311 & 249 & 251 & 205 & IS4 \\
\hline Pentachlorophenol & 30.394 & 266 & 264 & 268 & IS4 \\
\hline 4-n-Octylphenol & 30.448 & 107 & 206 & -- & IS4 \\
\hline Diazinon & 30.673 & 304 & 179 & 199 & IS4 \\
\hline Phenanthrene & 30.903 & 178 & 176 & 89 & IS4 \\
\hline Octylphenol, monoethoxy- (OPEO1) & 30.903 & 135 & 107 & 179 & IS4 \\
\hline Anthracene & 31.044 & 178 & 176 & 89 & IS4 \\
\hline Caffeine & 31.444 & 194 & 109 & 82 & IS4 \\
\hline $\begin{array}{l}\text { Hexahydrohexamethyl } \\
\text { cyclopentabenzopyran (HHCB) }\end{array}$ & 31.468 & 243 & 258 & 213 & IS4 \\
\hline Carbazole & 31.524 & 167 & 139 & 166 & IS4 \\
\hline $\begin{array}{l}\text { cetyl-hexamethyl-tetrahydro-naphthalene } \\
\text { (AHTN) }\end{array}$ & 31.538 & 243 & 258 & 197 & IS4 \\
\hline 4-Cumylphenol & 31.576 & 197 & 212 & -- & IS4 \\
\hline Carbaryl & 32.120 & 144 & 115 & 116 & IS4 \\
\hline Metalaxyl & 32.135 & 206 & 220 & 249 & IS4 \\
\hline Bromacil & 32.587 & 205 & 207 & -- & IS4 \\
\hline Metolachlor & 32.850 & 162 & 138 & 240 & IS4 \\
\hline Chlorpyrifos & 32.878 & 314 & 316 & 197 & IS4 \\
\hline Anthraquinone & 33.095 & 208 & 180 & 152 & IS4 \\
\hline Nonylphenol, monoethoxy- (total, NPEO1) & $33.1-33.9$ & 179 & 193 & 207 & IS4 \\
\hline Fluoranthene & 34.134 & 202 & 101 & 203 & IS4 \\
\hline Triclosan & 34.378 & 288 & 290 & 218 & IS4 \\
\hline Pyrene & 34.731 & 202 & 101 & 203 & IS5 \\
\hline Bisphenol A & 34.994 & 213 & 228 & 119 & IS5 \\
\hline Octylphenol, diethoxy-(OPEO2) & 35.168 & 223 & 135 & 294 & IS5 \\
\hline Nonylphenol, diethoxy- (total, NPEO2) & $35.7-36.5$ & 237 & 223 & 279 & IS5 \\
\hline Tri(dichloroisopropyl) phosphate & 36.400 & 379 & 383 & 381 & IS5 \\
\hline Tri(2-butoxyethyl) phosphate & 37.054 & 299 & 199 & 125 & IS5 \\
\hline Triphenyl phosphate & 37.176 & 326 & 325 & 215 & IS5 \\
\hline Diethylhexyl phthalate & 38.282 & 149 & 167 & 279 & IS5 \\
\hline
\end{tabular}


Table 2. Wastewater method compound retention time, quantitation ion, confirmation ions, surrogate compounds, and internal standard reference compound.-Continued

[Compounds are listed in order of retention time. min, minutes; m/z, mass-to-charge ratio; IS, internal standard; --, not used]

\begin{tabular}{|c|c|c|c|c|c|}
\hline Compound name & $\begin{array}{l}\text { Retention } \\
\text { time (min) }\end{array}$ & $\begin{array}{l}\text { Quantitation } \\
\text { ion }(\mathrm{m} / \mathrm{z})\end{array}$ & $\begin{array}{c}\text { Confirmation } \\
\text { ion }(\mathrm{m} / \mathrm{z})\end{array}$ & $\begin{array}{l}\text { Confirmation } \\
\text { ion }(\mathrm{m} / \mathrm{z})\end{array}$ & $\begin{array}{l}\text { Internal stan- } \\
\text { dard reference }\end{array}$ \\
\hline 2,2',4,4'-Tetrabromodiphenyl ether & 38.375 & 328 & 326 & 324 & IS5 \\
\hline Benzo $[a]$ pyrene & 41.431 & 252 & 250 & 126 & IS6 \\
\hline 3beta-Coprostanol & 42.927 & 373 & 355 & 388 & IS6 \\
\hline Cholesterol & 43.209 & 386 & 301 & 275 & IS6 \\
\hline beta-Sitosterol & 45.038 & 414 & 396 & 381 & IS6 \\
\hline beta-Stigmastanol & 45.193 & 416 & 401 & 233 & IS6 \\
\hline \multicolumn{6}{|l|}{ Surrogate Compounds } \\
\hline Decafluorobiphenyl & 18.786 & 334 & 265 & -- & IS2 \\
\hline Caffeine- $d_{9}$ & 31.444 & 197 & 110 & -- & IS4 \\
\hline Fluoranthene- $d_{10}$ & 34.087 & 212 & 106 & -- & IS4 \\
\hline Bisphenol A- $d_{11}$ & 34.947 & 216 & 234 & -- & IS4 \\
\hline \multicolumn{6}{|l|}{ Internal Standards } \\
\hline 1,4-Dichlorobenzene- $d_{4}$ (IS1) & 15.132 & 150 & 152 & -- & -- \\
\hline Naphthalene- $d_{8}$ (IS2) & 21.048 & 136 & -- & -- & -- \\
\hline Acenaphthene- $d_{10}$ (IS3) & 26.700 & 164 & 162 & 160 & -- \\
\hline Phenanthrene- $d_{10}$ (IS4) & 30.842 & 188 & -- & -- & -- \\
\hline Chrysene- $d_{12}$ (IS5) & 38.010 & 240 & -- & -- & -- \\
\hline Perylene- $d_{12}$ (IS6) & 41.558 & 264 & 132 & -- & -- \\
\hline
\end{tabular}


and also has been used in other studies (Blackburn and Waldock, 1995).

10.4 A third-party check (TPC) solution of the method compounds obtained from an independent source from the calibration mixture must be analyzed to verify the calibration solution concentrations (see section 6.7). The compound concentrations calculated in the TPC must be within \pm 30 percent of the expected concentration. If the TPC sample concentrations do not fall within the \pm 30 -percent window, the source of the error must be determined and corrected before environmental samples are analyzed.

\section{Quality Assurance and Quality Control}

The NWQL has prepared a laboratory quality management document (Maloney, 2005) and quality-assurance and quality-control (QA/QC) guidance document (M.R. Burkhardt and T.J. Maloney, U.S. Geological Survey, written commun., 1998) for processing and analyzing samples for laboratory analytical services. These documents are followed for this method to establish and verify data quality. The samplematrix, sample-preparation, and sample-analysis steps are evaluated to determine data quality for each sample individually, and for all samples as part of a sample-preparation set and a sample-analysis set.

Problematic sample matrices will affect the performance of the method during sample preparation and analysis. Extremely complex sample matrices, such as raw sewage, are discouraged because they require additional equipment and instrument cleaning as outlined in section 7.10.

Before sample holding-time expiration, each environmental sample is prepared for analysis as part of a sample-preparation set that contains as many as 18 environmental samples, a laboratory reagent spike, and blank (control) to monitor method performance. It is unlikely, however, that a unique sample matrix will perform similarly to the recoveries of compounds and surrogates in the set spike and blank. Control limits for laboratory spikes in reagent water are set at the mean percent recovery \pm 3 standard deviations.

Surrogate compounds (chemically representative of most method compounds) are added to each sample prior to preparation. Surrogate standard recoveries are used to measure gross sample-processing problems and matrix effects. Control limits for surrogates are set at the mean percent recovery \pm 3 standard deviations as compiled from reagent water laboratory set spike and blank sample data. The recoveries of caffeine- $d_{9}$, fluoranthene- $d_{10}$, and bisphenol A- $d_{11}$ may be used to monitor sample preparation and potential matrix effects for their respective nonisotopically labeled analogs, as well as other chemically similar (by functionality, reactivity, or volatility) compounds. Surrogate recoveries generally need to be used to evaluate specific sample-preparation steps and are of limited use for assessing method compound recoveries. Concentrations reported by the NWQL for compounds and surrogates in environmental samples are never corrected for spike or surrogate recoveries. However, spike and surrogate recoveries provide data on method performance that is useful for interpretation of environmental sample data.

Set blanks provide information regarding possible contamination introduced to the sample at the laboratory. Possible contamination from field and sample handling is not monitored unless the appropriate field blanks are submitted to the laboratory for analysis. Some compounds in this method are common in personal-care products and might be detected in laboratory blanks. If compounds are detected in more than 10 percent of the historical laboratory blanks, they are treated as though they are always potentially present in sample background.

As a part of a field quality-control program, the NWQL suggests that customers include some laboratory matrix spike samples in their projects. The NWQL has prepared a spiking solution that is available at One-Stop Shopping (catalog number N1430). Laboratory matrix spike samples also can be requested if a duplicate sample is submitted (U.S. Geological Survey, 2005).

NOTE: These matrix spike samples can be requested by shipping a duplicate sample and separate analytical services request (ASR) form with "NWQL SPIKE" indicated in the field "Comment to NWQL." An amount equivalent to $2 \mu \mathrm{g} / \mathrm{L}$ (for most compounds) is spiked at the laboratory.

Sample extracts are analyzed in an instrument batch or sequence (table 3 ) to provide additional information for quality assurance and facilitate corrective actions that might be required if performance criteria are not met.

The analytical sequence includes a laboratory set spike and set blank sample. Continuing calibration verification solutions are analyzed at designated intervals (every sample preparation set) to check that the instrument is in compliance with initial calibration criteria. Compounds that are quantitatively reported (not permanently flagged as an estimated concentration in data reports) must have a calculated concentration within \pm 25 percent of the expected CCV concentration. The Quality Management System document (Maloney, 2005) requires three CCV check solutions to be analyzed every 24 hours. Finally, low-concentration standards equivalent to $1 \mu \mathrm{g} / \mathrm{L}$ (or less) are analyzed in each sequence before and after the environmental samples to ensure that instrument sensitivity is maintained throughout the sample sequence. If the instrument does not meet acceptance criteria, then follow suggested procedures of cleaning and maintenance (see Section 9.1, GC performance evaluation) to bring the instrument into compliance.

Each sample also has a PAH procedural internal standard solution added to correct for slight differences in extract volume and to adjust for slight variations in instrumental performance. The procedural internal standards are added prior to instrument analysis and are used to monitor instrument conditions, such as extract injection-volume variations, unexpected GC compound retention time shifts, or instrument abnormalities caused by power interruptions or component malfunctions. 
Table 3. Typical analytical sequence suggested for use with this method.

[CCV, continuing calibration verification; $\mathrm{ng} / \mu \mathrm{L}$, nanogram per microliter]

\begin{tabular}{cl}
$\begin{array}{c}\text { Injection vial } \\
\text { sequence }\end{array}$ & \multicolumn{1}{c}{ Sample description } \\
\hline 1 & Calibration level $7(10 \mathrm{ng} / \mu \mathrm{L})^{1}$ \\
2 & Calibration level $6(5 \mathrm{ng} / \mu \mathrm{L})^{1}$ \\
3 & Calibration level $5(2 \mathrm{ng} / \mu \mathrm{L})^{1}$ \\
4 & Calibration level $4(1 \mathrm{ng} / \mu \mathrm{L})^{1}$ \\
5 & Calibration level 3 $(0.5 \mathrm{ng} / \mu \mathrm{L})^{1}$ \\
6 & Calibration level 2 $(0.2 \mathrm{ng} / \mu \mathrm{L})^{1}$ \\
7 & Calibration level 1 $(0.1 \mathrm{ng} / \mu \mathrm{L})^{1}$ \\
8 & Instrument detection level standard $(1 \mathrm{ng} / \mu \mathrm{L}$, calibration level 4) \\
9 & Preparation set one method spike \\
10 & Preparation set one method blank \\
$11-20$ & Set of 10 or less environmental samples for set one \\
21 & CCV (calibration level 3, 4, or 5; for set one and set two) \\
22 & Preparation set two method spike \\
23 & Preparation set two method blank \\
$24-33$ & Set of 10 or less environmental samples for set two \\
34 & CCV (calibration level 3, 4, or 5; for set two) \\
35 & Instrument detection level standard (1 ng/ $\mu \mathrm{L}$, calibration level 4) \\
\hline
\end{tabular}

${ }^{1}$ The sequence order of calibration solutions is not important.

It is difficult to troubleshoot partial QA/QC problems caused by a combination of a complex sample matrix, samplepreparation errors, or a marginally acceptable analysis. Certain process failures require sample preparation to be repeated if a duplicate sample has been provided to the NWQL. Other failures might be identified as "matrix-induced" and be impossible to correct, thus requiring associated data qualifiers for reporting results. In rare cases, certain failures, such as surrogate recoveries that are not within control limits, might indicate that sample results should not be reported, or be qualified. If this is the case, the data can be transmitted three ways: estimated ("E" remark coded), a raised reporting level, or the data are reported as deleted - ruined $(\mathrm{D}-\mathrm{R})$.

\section{Calculation of Results}

Before quantitative results are reported, each compound first must meet qualitative criteria.

\subsection{Qualitative identification}

The retention time of the quantitation ion for the compound of interest should be within 0.1 minute of the expected relative retention time in the absence of any obvious matrix effects. Furthermore, the profiles of the qualification and quantification ion peaks must maximize within two scans of each other (in the absence of any obvious interference). Visually compare the sample compound spectra to the reference standard spectra and confirm that they match. The GC/MS operator must visually compare reference spectra, integrated ion ratios of the quantitation ion to two confirmation ions, and the elution of ion profiles to determine if the spectral match between standards and samples is reasonable. Peak area ratios of the quantification and qualifier ions must agree within \pm 20 percent between standards and samples for concentrations greater than the minimum reporting level (MRL) in the absence of any obvious coeluting interference.

NOTE: Occasionally, ion(s) can appear to be missing or ion abundance ratios can appear to be distorted in the spectrum of a compound in a sample when compared to the reference spectrum, especially at concentrations near the MDL if there is interfering spectral contamination. A distorted sample spectrum often results from automatic data-processing routines that subtract the average of the two spectra before and after the spectrum at the apex of the peak. In this situation, a compound can be positively identified if the ion profiles maximize within two scans of each other (after accounting for any obvious interferences to ion profiles, if necessary).

\subsection{Quantitation}

12.2.1 Determination of single-component compounds. After a compound has passed qualitative criteria, the concentration is calculated according to the calibration curve used to establish the best fit with the calibration points. Curve-fitting routines provided by the instrument manufacturer and described in a similar NWQL method report (Sandstrom and others, 2001) are used to obtain a calibration curve for each compound. If the calculated concentration of a compound exceeds 
the highest concentration point of the calibration curve, add higher concentration calibration solutions to the curve or dilute the extract to bring the compound response within the range of the calibration curve. Concentration results must be reported as estimated with the "E" remark code if compound response is less than the lowest point on the calibration curve or the interim reporting level (IRL). If curve-fitting routines (quadratic curves and power curves) are used for calibration, verify that the sample compound response is not outside the working range of the calibration curve (or in a region of unexpected deviations in the calibration curve), or recalculate the concentration by using another type of calibration curve.

\subsubsection{Determination of multicomponent compounds. The} 4-NPs, NPEO1, and NPEO2 technical mixtures are each composed of 10 to 20 discernible isomers. Manually integrate the isomeric peak areas of their respective quantitation ions present in their expected retention time window range (table 2), similar to the calibration process described earlier (Section 10, Instrument Calibration) for these compounds. The spectra of each isomeric GC peak of a multicomponent compound are checked for interference. If interferences cause the ratios of the confirmation ions to the quantification ion to be unreasonable, then integrate that portion of the ion chromatogram that is caused by the contamination or interference and subtract the interference from the total.

NOTE: This procedure seldom is necessary because the quantitation and confirmation ions for 4-NP, NPEO1, and NPEO2 normally are free from coeluting interference.

\subsection{Reporting results}

Data are reported according to the NWQL laboratory quality management document (Maloney, 2005; Childress and others, 1999) and a quality-assurance and quality-control (QA/ QC) guidance document (M.R. Burkhardt and T.J. Maloney, U.S. Geological Survey, written commun., 1998). Alphanumeric data-qualifier codes are used to report information about the presence and concentration of a compound when concentrations are less certain because of matrix effects, interferences, and other unexpected circumstances.

The wastewater method is considered to be "informationrich" (Childress and others, 1999) because compound identifications are determined by mass spectrometry; consequently, results are not censored at the IRL. Compound concentrations, therefore, are reported as follows.

If the concentration is equal to or greater than the IRL, the concentration is reported to three significant figures. If the concentration is less than either the IRL or the lowest calibration standard (usually $0.2-\mu \mathrm{g} / \mathrm{L}$ ), results are reported by using the "E" code to indicate that it has been estimated. Other instances where it is appropriate to use the " $E$ " code have been documented (Maloney, 2005; Childress and others, 1999). They include matrix interferences, compounds that have been permanently assigned an "E" remark code, and those compounds that do not meet quality-assurance criteria, such as being out of calibration by more than \pm 25 percent. If the calculated result is greater than the highest concentration standard in the calibration curve, then the sample is diluted into the range of the calibration curve and reanalyzed, or higher calibration standards are added to the curve to bracket the sample result. If dilution is not possible, concentration results can be reported with an "E" remark code.

Reporting compound results as estimated, because their concentrations are less than the IRL, does not decrease confidence in qualitative identification. However, concentrations reported near or less than the MDL need to be interpreted cautiously. If compounds are barely discernible in mass spectra and responses are near or less than the MDL, then the potential for reporting false detections (false positives) or mistakenly reporting compounds as not present (false negatives) increases. When there is doubt about qualitative identification, reporting conservative results (less than IRL) is appropriate.

Compounds present in over 10 percent of the historical laboratory blanks are referred to as chronic blank compounds and are treated as if present in all samples. Consequently, no data (not even estimated data with an "E" remark code) will be reported less than the $95^{\text {th }}$ percentile of the historical laboratory blank concentration levels for chronic blank compounds. If the $95^{\text {th }}$ percentile is greater than the IRL derived from the calculated MDL, the IRL is raised to the $95^{\text {th }}$ percentile.

NOTE: Laboratory blanks are evaluated annually for contamination.

\section{Results and Discussion of Method Validation}

Reagent-water (Solution 2000 water) samples, surfacewater samples collected from the Platte River in Confluence Park, Denver, Colo., and ground-water samples collected from a domestic well near Evergreen, Colo., were used to test method performance. One set of 1-L subsamples was fortified at a lower concentration $(0.5-10 \mu \mathrm{g} / \mathrm{L})$ of each compound and another set was fortified at a concentration 8 times higher $(4.0-80 \mu \mathrm{g} / \mathrm{L})$ of each compound. In addition, the three sample matrices were extracted and analyzed unfortified (table 4) to determine the natural presence of any method compounds.

The presence of 10 compounds in the unspiked reagentwater sample (table 4) reemphasizes the ubiquitous nature of many of the method compounds, as well as the importance of avoiding contamination throughout sample collection, preparation, and analysis. Therefore, if contamination is detected in the set blank, or if the compound is chronic, the concentration of the compound in an environmental sample is not reported less than the set blank concentration or $95^{\text {th }}$ percentile concentration (for chronic compounds), or whichever concentration is greater. 
Table 4. Wastewater method compounds detected in unfortified reagent-water, ground-water, and surface-water samples.

[ $\mu \mathrm{g} / \mathrm{L}$, micrograms per liter; --, not detected; $\mathrm{N}$, number of samples]

\begin{tabular}{|c|c|c|c|}
\hline \multirow[b]{2}{*}{ Compound name } & \multicolumn{3}{|c|}{ Median concentration ( $\mu \mathrm{g} / \mathrm{L})$} \\
\hline & $\begin{array}{c}\text { Reagent } \\
(\mathrm{N}=7)\end{array}$ & $\begin{array}{c}\text { Ground } \\
(\mathrm{N}=3)\end{array}$ & $\begin{array}{c}\text { Surface } \\
(\mathrm{N}=3)\end{array}$ \\
\hline 1,4-Dichlorobenzene & -- & -- & -- \\
\hline 1-Methylnaphthalene & -- & -- & -- \\
\hline 2,2',4,4'-Tetradibromodiphenyl ether & -- & -- & -- \\
\hline 2,6-Dimethylnaphthalene & -- & -- & -- \\
\hline 2-Methylnaphthalene & 0.01 & -- & 0.02 \\
\hline 3beta-Coprostanol & -- & -- & .26 \\
\hline 3-Methyl-1H-indole (skatol) & -- & -- & -- \\
\hline 3-tert-Butyl-4-hydroxyanisole (BHA) & -- & -- & -- \\
\hline 3,4-Dichlorophenyl isocyanate & -- & -- & .08 \\
\hline 4-Cumylphenol & -- & -- & -- \\
\hline 4-n-Octylphenol & -- & -- & -- \\
\hline 4-Nonylphenol (total) & -- & -- & 1.20 \\
\hline 4-tert-Octylphenol & .10 & -- & .16 \\
\hline 5-Methyl-1H-benzotriazole & -- & -- & 1.30 \\
\hline Acetophenone & .04 & -- & -- \\
\hline $\begin{array}{l}\text { Acetyl-hexamethyl-tetrahydro-naphthalene } \\
\text { (AHTN) }\end{array}$ & -- & -- & .21 \\
\hline Anthracene & -- & -- & -- \\
\hline Anthraquinone & -- & 0.02 & -- \\
\hline Atrazine & -- & -- & -- \\
\hline Benzo $[a]$ pyrene & -- & -- & -- \\
\hline Benzophenone & -- & .09 & .17 \\
\hline beta-Sitosterol & -- & -- & -- \\
\hline beta-Stigmastanol & -- & -- & -- \\
\hline Bisphenol A & -- & -- & .21 \\
\hline Bromacil & -- & -- & -- \\
\hline Bromoform & -- & -- & -- \\
\hline Caffeine & -- & .03 & .20 \\
\hline Camphor & .04 & -- & .04 \\
\hline Carbaryl & -- & -- & -- \\
\hline Carbazole & -- & -- & -- \\
\hline Chlorpyrifos & -- & -- & -- \\
\hline Cholesterol & .50 & -- & .96 \\
\hline Cotinine & -- & -- & .41 \\
\hline Diazinon & -- & -- & -- \\
\hline
\end{tabular}


Table 4. Wastewater method compounds detected in unfortified reagent-water, ground-water, and surface-water samples-Continued.

[ $\mu \mathrm{g} / \mathrm{L}$, micrograms per liter; --, not detected; N, number of samples]

\begin{tabular}{|c|c|c|c|}
\hline \multirow[b]{2}{*}{ Compound name } & \multicolumn{3}{|c|}{ Median concentration $(\mu \mathrm{g} / \mathrm{L})$} \\
\hline & $\begin{array}{c}\text { Reagent } \\
(\mathrm{N}=7)\end{array}$ & $\begin{array}{l}\text { Ground } \\
(\mathrm{N}=3)\end{array}$ & $\begin{array}{c}\text { Surface } \\
(\mathrm{N}=3)\end{array}$ \\
\hline Dichlorvos & -- & -- & -- \\
\hline Diethylhexyl phthalate & 0.15 & -- & 0.33 \\
\hline Diethyl phthalate & .08 & 0.13 & .11 \\
\hline$d$-Limonene & -- & -- & -- \\
\hline Fluoranthene & -- & .03 & .04 \\
\hline Hexahydrohexamethyl cyclopentabenzopyran (HHCB) & -- & -- & .89 \\
\hline Indole & -- & -- & -- \\
\hline Isoborneol & -- & -- & -- \\
\hline Isophorone & -- & -- & -- \\
\hline Isopropylbenzene (cumene) & -- & -- & -- \\
\hline Isoquinoline & -- & -- & -- \\
\hline Menthol & -- & -- & -- \\
\hline Metalaxyl & -- & -- & -- \\
\hline Methyl salicylate & -- & -- & -- \\
\hline Metolachlor & -- & -- & -- \\
\hline N,N-Diethyl-meta-toluamide (DEET) & -- & -- & .24 \\
\hline Naphthalene & .01 & -- & .03 \\
\hline Nonylphenol, diethoxy- (total, NPEO2) & -- & -- & 2.80 \\
\hline Nonylphenol, monoethoxy- (total, NPEO1) & -- & -- & 1.60 \\
\hline Octylphenol, diethoxy- (OPEO2) & -- & -- & .19 \\
\hline Octylphenol, monoethoxy- (OPEO1) & -- & -- & .88 \\
\hline$p$-Cresol & -- & -- & -- \\
\hline Pentachlorophenol & -- & -- & .40 \\
\hline Phenanthrene & .02 & .04 & .03 \\
\hline Phenol & .05 & -- & .07 \\
\hline Prometon & -- & -- & -- \\
\hline Pyrene & -- & .02 & .04 \\
\hline Tetrachloroethylene & -- & .30 & .01 \\
\hline Tri(2-chloroethyl) phosphate & -- & -- & .21 \\
\hline Tri(dichloroisopropyl) phosphate & -- & -- & .23 \\
\hline Tributyl phosphate & -- & -- & -- \\
\hline Triclosan & -- & -- & .15 \\
\hline Triethyl citrate (ethyl citrate) & -- & -- & .13 \\
\hline Triphenyl phosphate & -- & -- & .10 \\
\hline Tri(2-butoxyethyl) phosphate & -- & .10 & .40 \\
\hline
\end{tabular}


Mean bias and variability data from analyses of the fortified matrices (background corrected as necessary) are listed in table 5 .

Recoveries in reagent-water samples fortified at $0.5 \mu \mathrm{g} / \mathrm{L}$ averaged 72 percent \pm 8 percent relative standard deviation. The concentration of 21 compounds is always reported as estimated for one of three reasons: unacceptably low-biased recovery (less than 60 percent) or highly variable method performance (greater than 25 percent RSD), unstable instrument response, or reference standards prepared from technical mixtures. Furthermore, nine additional compounds (see footnote 4 , table 5) demonstrated the potential for variable performance during some portion of this initial method validation. The concentration of these compounds also will be estimated if the set spike recovery or expected set CCV concentrations are not within control limits (see section 11). The initial MDLs were calculated for compounds in reagent water by using the corresponding spike concentration as listed in table 5 .

The MDL is defined as the minimum concentration of a substance that can be measured and reported with 99-percent confidence that the compound concentration is greater than zero (U.S. Environmental Protection Agency, 1997b). Initial MDLs were determined according to the procedure outlined by the U.S. Environmental Protection Agency (1997b).

The MDL was calculated according to the equation

$$
M D L=S \cdot t(n-1,1-\alpha=0.99),
$$

\begin{tabular}{|c|c|c|}
\hline where & $S=$ & $\begin{array}{l}\text { standard deviation of } \\
\text { replicate analyses, in } \\
\text { microgram per liter, at the } \\
\text { lowest spike concentration; } \\
\text { number of replicate analyses; }\end{array}$ \\
\hline$t_{(n-1,}$ & $0.99)=$ & $\begin{array}{l}\text { Student's } t \text {-value for the } 99- \\
\text { percent confidence level } \\
\text { with } n-1 \text { degrees of freedom. }\end{array}$ \\
\hline
\end{tabular}

According to the USEPA procedure, at least seven replicate reagent-water samples are fortified with compounds at concentrations of two to five times the calculated MDL. This concentration range was used to calculate initial MDLs (table 6). Initial MDLs for various method compounds were calculated by using concentrations higher than the desired spiking level so that the compound would be detected in each of the replicate reagent-water samples. Initial MDLs that were calculated by using fortified concentrations higher than the approved spiking amount have been defined as estimated MDLs, and have been footnoted as such in table 6. Initial MDLs that were calculated from this procedure ranged from 0.02 to $1.35 \mu \mathrm{g} / \mathrm{L}$ and averaged $0.18 \mu \mathrm{g} / \mathrm{L}$.

The IRLs have been set higher (two to ten times for most compounds) than the calculated initial MDLs (table 6). This precaution reduces the risk of reporting that a compound is undetected (less than the IRL), when it is actually in the sample near the MDL concentration (Childress and others,
1999). All qualitatively identified compounds detected less than the IRL are reported as estimated, regardless of the established IRL, because this wastewater method is classified as an "information-rich" method, as are other mass spectrometric methods (Childress and others, 1999). Furthermore, there was no need to raise any of the initial IRLs because of chronic blank contamination (see table 4).

The IRLs will be updated annually as necessary by using data acquired from the NWQL long-term method detection level (LT-MDL) program (Childress and others, 1999). The LT-MDL is calculated with 6 to 12 months of data, and includes results from multiple instruments, analysts, and calibration curves. Laboratory blank data also will be evaluated annually.

A boxplot of the CLLE extraction results for 140 environmental samples collected throughout the United States, with the majority from urban sampling sites, is shown in figure 3. The data are reported using a log scale to accommodate the large concentration ranges for each compound. The data include estimated concentrations reported less than the IRL. At least one method compound was found in every environmental sample analyzed. The most frequently detected compounds were caffeine and DEET, which were detected in 67 percent (94 out of 140) of the environmental samples.

\section{Summary and Conclusions}

The U.S. Geological Survey (USGS) National Water Quality Laboratory has developed an analytical method (O-4433-06) for the determination of 69 compounds typically found in domestic and industrial wastewater. The method provides an efficient means for detecting emerging toxic and estrogenic compounds that otherwise might not be reported because they are unregulated or not included in other USGS or U.S. Environmental Protection Agency methods. Whole-water samples are extracted using continuous liquid-liquid extraction with dichloromethane, and compounds are determined by capillary-column gas chromatography/mass spectrometry. The method focuses on the determination of compounds that are an indicator of wastewater, exhibit endocrine-disrupting potential or toxicity, or have widespread use. Determination of the alkylphenol ethoxylate nonionic surfactant compounds is particularly important because they are persistent indicators of wastewater. Other method compounds are representative of fragrances, food additives, antioxidants, flame retardants, plasticizers, industrial solvents, disinfectants, fecal sterols, polycyclic aromatic hydrocarbons, and high-use domestic pesticides.

Average recovery of all method compounds for shortterm single-operator results in reagent-water samples fortified at 0.5 microgram per liter was $72 \pm 8$ percent relative standard deviation and initial method detection limits averaged 0.18 microgram per liter. The compound recoveries and interim reporting levels for this whole-water continuous liquid-liquid 
Table 5. Wastewater method mean bias and variability of spike-recovery data for eight replicates with compounds spiked at two concentrations that range from 0.5 to 80 micrograms per liter in reagent-water (including calculated method detection limits), groundwater, and surface-water samples.

[ $\mu \mathrm{g} / \mathrm{L}$, micrograms per liter; \%, percent; CCV, continuing calibration verification solution; RSD, relative standard deviation; MDL, method detection limit; --, not applicable]

\begin{tabular}{|c|c|c|c|c|c|c|c|c|}
\hline \multirow{2}{*}{ Compound name } & \multirow{2}{*}{$\begin{array}{c}\text { Spike } \\
\text { amount } \\
\text { ( } \mu \mathrm{g} / \mathrm{L})\end{array}$} & \multicolumn{3}{|c|}{ Mean \% recovery } & \multicolumn{3}{|c|}{$\%$ RSD } & \multirow{2}{*}{$\begin{array}{c}\text { Initial } \\
\text { MDL } \\
\text { ( } \mu \mathrm{g} / \mathrm{L})\end{array}$} \\
\hline & & Reagent & Ground & Surface & Reagent & Ground & Surface & \\
\hline \multirow{2}{*}{$\begin{array}{l}\text { 2,2',4,4'-Tetrabromodiphenyl } \\
\text { ether }\end{array}$} & 4.0 & 48.82 & 64.86 & 56.43 & 8.81 & 6.72 & 9.38 & \\
\hline & .5 & 68.86 & 62.29 & 48.57 & 9.76 & 6.27 & 14.21 & 0.11 \\
\hline \multirow[t]{2}{*}{ 3beta-Coprostanol ${ }^{4}$} & 16.0 & 55.94 & 67.73 & $60.73^{*}$ & 8.93 & 26.15 & 34.90 & \\
\hline & 2.0 & 62.50 & 88.93 & $109.91^{*}$ & 10.58 & 20.49 & 19.25 & .38 \\
\hline \multirow[t]{2}{*}{ 3-Methyl-1H-indole (skatol) ${ }^{4}$} & 4.0 & 67.91 & 76.04 & 70.36 & 38.70 & 25.61 & 43.33 & \\
\hline & .5 & 81.71 & 97.14 & 86.86 & 5.55 & 6.16 & 11.19 & .07 \\
\hline \multirow[t]{2}{*}{ 4-Cumylphenol } & 4.0 & 83.19 & 87.46 & 92.25 & 8.56 & 8.48 & 9.75 & \\
\hline & .5 & 74.57 & 84.00 & 92.57 & 10.92 & 6.59 & 11.41 & .13 \\
\hline \multirow[t]{2}{*}{ 4-n-Octylphenol } & 4.0 & 83.22 & 93.43 & 91.61 & 8.14 & 8.77 & 9.91 & \\
\hline & .5 & 78.00 & 99.71 & 103.71 & 9.48 & 6.17 & 9.73 & .11 \\
\hline \multirow[t]{2}{*}{ 4-tert-Octylphenol } & 4.0 & $82.31^{*}$ & 94.68 & $81.62^{*}$ & 3.03 & 9.87 & 7.52 & \\
\hline & .5 & $3.71^{*}$ & 101.71 & $80.82^{*}$ & 8.85 & 5.95 & 9.41 & .11 \\
\hline \multirow[t]{2}{*}{ 5-Methyl-1H-benzotriazle ${ }^{4}$} & 16.0 & 42.96 & 109.32 & $139.82^{*}$ & 28.20 & 26.67 & 13.39 & \\
\hline & 2.0 & 53.50 & 83.07 & $108.00^{*}$ & 10.48 & 9.26 & 5.59 & .35 \\
\hline \multirow[t]{2}{*}{ Acetophenone } & 4.0 & $88.38^{*}$ & 88.54 & 102.64 & 8.38 & 10.24 & 11.24 & \\
\hline & .5 & $77.28^{*}$ & 97.71 & 129.71 & 5.83 & 6.08 & 10.44 & .07 \\
\hline \multirow{2}{*}{$\begin{array}{l}\text { Acetyl-hexamethyl-tetrahydro- } \\
\text { naphthalene (AHTN) }\end{array}$} & 4.0 & 81.41 & 89.11 & 85.68 & 8.36 & 7.47 & 9.75 & \\
\hline & .5 & 73.43 & 86.57 & 109.14 & 10.03 & 6.22 & 12.15 & .11 \\
\hline \multirow[t]{2}{*}{ Anthracene } & 4.0 & 78.72 & 86.32 & 82.82 & 8.45 & 8.80 & 9.50 & \\
\hline & .5 & 70.00 & 82.29 & 85.43 & 7.38 & 6.65 & 11.92 & .08 \\
\hline \multirow[t]{2}{*}{ Anthraquinone } & 4.0 & 66.31 & $66.41^{*}$ & 75.18 & 8.86 & 9.92 & 8.21 & \\
\hline & .5 & 66.00 & $64.00^{*}$ & 88.57 & 7.82 & 6.98 & 8.52 & .08 \\
\hline \multirow{2}{*}{ Atrazine $^{4}$} & 4.0 & 71.22 & 81.71 & 67.68 & 39.90 & 16.13 & 34.68 & \\
\hline & .5 & 78.00 & 85.43 & 82.29 & 6.94 & 7.49 & 10.63 & .08 \\
\hline \multirow[t]{2}{*}{ Benzo $[a]$ pyrene } & 4.0 & 86.72 & 90.96 & 82.61 & 13.40 & 8.66 & 9.53 & \\
\hline & .5 & 74.57 & 87.43 & 77.43 & 5.30 & 5.86 & 15.19 & .06 \\
\hline \multirow[t]{2}{*}{ Benzophenone } & 4.0 & 86.38 & $80.66^{*}$ & $100.67^{*}$ & 7.86 & 10.38 & 7.67 & \\
\hline & .5 & 76.00 & $78.48^{*}$ & $86.18^{*}$ & 8.32 & 6.55 & 8.74 & .10 \\
\hline \multirow[t]{2}{*}{ beta-Stigmastanol $^{4}$} & 16.0 & 45.30 & 62.73 & 49.54 & 36.6 & 28.92 & 33.32 & \\
\hline & 2.0 & 67.00 & 85.93 & 95.64 & 5.24 & 11.56 & 19.60 & .22 \\
\hline \multirow[t]{2}{*}{ Bisphenol $\mathrm{A}^{4}$} & 4.0 & 68.13 & 82.96 & $76.58^{*}$ & 3.98 & 13.46 & 11.24 & \\
\hline & .5 & 46.29 & 101.14 & $63.14^{*}$ & 2.24 & 7.81 & 10.81 & .22 \\
\hline \multirow[t]{2}{*}{ Bromacil } & 4.0 & 78.45 & 85.38 & 89.04 & 10.10 & 14.30 & 8.46 & \\
\hline & .5 & 70.57 & 93.79 & 114.39 & 7.76 & 7.41 & 10.10 & .10 \\
\hline
\end{tabular}


Table 5. Wastewater method mean bias and variability of spike-recovery data for eight replicates with compounds spiked at two concentrations that range from 0.5 to 80 micrograms per liter in reagent-water (including calculated method detection limits), groundwater, and surface-water samples-Continued.

[ $\mu \mathrm{g} / \mathrm{L}$, micrograms per liter; \%, percent; CCV, continuing calibration verification solution; RSD, relative standard deviation; MDL, method detection limit; --, not applicable

\begin{tabular}{|c|c|c|c|c|c|c|c|c|}
\hline \multirow{2}{*}{ Compound name } & \multirow{2}{*}{$\begin{array}{c}\text { Spike } \\
\text { amount } \\
\text { ( } \mu \mathrm{g} / \mathrm{L} \text { ) }\end{array}$} & \multicolumn{3}{|c|}{ Mean \% recovery } & \multicolumn{3}{|c|}{$\%$ RSD } & \multirow{2}{*}{$\begin{array}{c}\text { Initial } \\
\text { MDL } \\
\text { ( } \mu \mathrm{g} / \mathrm{L})\end{array}$} \\
\hline & & Reagent & Ground & Surface & Reagent & Ground & Surface & \\
\hline \multirow[t]{2}{*}{ Caffeine } & 4.0 & 73.00 & $77.17^{*}$ & $80.55^{*}$ & 13.80 & 13.61 & 8.89 & \\
\hline & .5 & 74.86 & $84.60^{*}$ & $72.00^{*}$ & 5.31 & 7.48 & 8.98 & 0.06 \\
\hline \multirow[t]{2}{*}{ Camphor } & 4.0 & $79.58^{*}$ & 80.39 & $82.42^{*}$ & 8.26 & 12.41 & 9.16 & \\
\hline & .5 & $71.49^{*}$ & 82.00 & $78.32^{*}$ & 5.84 & 6.90 & 11.58 & .09 \\
\hline \multirow[t]{2}{*}{ Carbazole } & 4.0 & 78.16 & 89.43 & 88.25 & 14.60 & 9.89 & 12.16 & \\
\hline & .5 & 96.00 & 93.94 & 104.86 & 7.68 & 5.40 & 10.32 & .12 \\
\hline \multirow[t]{2}{*}{ Chlorpyrifos } & 4.0 & 83.28 & 91.18 & 85.00 & 8.42 & 6.02 & 10.53 & \\
\hline & .5 & 78.57 & 87.14 & 78.29 & 9.61 & 5.44 & 15.36 & .12 \\
\hline \multirow[t]{2}{*}{ Cholesterol $^{4}$} & 16.0 & $55.58^{*}$ & 69.08 & $63.52^{*}$ & 20.30 & 29.93 & 33.74 & \\
\hline & 2.0 & $60.14^{*}$ & 88.43 & $85.80^{*}$ & 7.77 & 17.13 & 15.38 & .30 \\
\hline \multirow[t]{2}{*}{ Diazinon } & 4.0 & 77.28 & 83.07 & 89.82 & 10.00 & 6.74 & 10.56 & \\
\hline & .5 & 77.43 & 88.00 & 96.29 & 9.63 & 10.42 & 11.59 & .11 \\
\hline \multirow{2}{*}{ Diethylhexyl phthalate (DEHP) } & 4.0 & $81.06^{*}$ & 159.57 & $82.08^{*}$ & 12.00 & 76.26 & 18.76 & 85 \\
\hline & .5 & $90.20^{*}$ & 225.33 & $49.45^{*}$ & 40.78 & 7.73 & 18.21 & .85 \\
\hline \multirow[t]{2}{*}{ Diethyl phthalate (DEP) } & 4.0 & $86.31^{*}$ & 90.82 & $97.05^{*}$ & 7.89 & 10.86 & 9.00 & \\
\hline & .5 & $76.08^{*}$ & 104.29 & $91.15^{*}$ & 8.03 & 6.50 & 11.93 & .10 \\
\hline \multirow[t]{2}{*}{ Fluoranthene } & 4.0 & 80.78 & $89.34^{*}$ & $82.86^{*}$ & 8.19 & 8.75 & 9.17 & \\
\hline & .5 & 79.43 & $84.32^{*}$ & $80.44^{*}$ & 6.35 & 5.22 & 11.03 & .08 \\
\hline \multirow{2}{*}{$\begin{array}{l}\text { Hexahydrohexamethyl-cyclo- } \\
\text { pentabenzopyran }(\mathrm{HHCB})^{4}\end{array}$} & 4.0 & 80.59 & 88.57 & $81.53^{*}$ & 9.23 & 8.17 & 9.25 & \\
\hline & .5 & 74.86 & 88.29 & $124.57^{*}$ & 9.74 & 5.62 & 12.15 & .11 \\
\hline \multirow[t]{2}{*}{ Indole } & 4.0 & 69.75 & 70.11 & 62.86 & 38.80 & 35.39 & 41.13 & \\
\hline & .5 & 80.86 & 91.71 & 67.14 & 6.36 & 7.17 & 19.06 & .08 \\
\hline \multirow[t]{2}{*}{ Isoborneol } & 4.0 & 71.69 & 76.18 & 79.07 & 38.40 & 15.68 & 8.15 & \\
\hline & .5 & 78.00 & 85.71 & 95.14 & 3.92 & 7.55 & 10.14 & .05 \\
\hline \multirow[t]{2}{*}{ Isophorone } & 4.0 & 81.97 & 86.64 & 85.43 & 9.09 & 16.58 & 8.84 & \\
\hline & .5 & 79.14 & 87.71 & 97.71 & 6.34 & 6.37 & 11.18 & .08 \\
\hline \multirow[t]{2}{*}{ Isoquinoline } & 4.0 & 75.44 & 79.96 & 90.79 & 14.20 & 16.72 & 9.61 & \\
\hline & .5 & 76.00 & 95.43 & 115.71 & 7.75 & 10.53 & 11.91 & .09 \\
\hline \multirow[t]{2}{*}{ Menthol } & 4.0 & 79.13 & 79.47 & 82.50 & 10.70 & 14.89 & 8.15 & \\
\hline & .5 & 76.00 & 81.71 & 98.00 & 4.56 & 7.80 & 7.99 & .05 \\
\hline \multirow[t]{2}{*}{ Metalaxyl } & 4.0 & 85.38 & 90.82 & 100.36 & 9.03 & 10.32 & 9.96 & \\
\hline & .5 & 79.14 & 98.00 & 107.14 & 10.30 & 7.64 & 12.09 & .13 \\
\hline \multirow[t]{2}{*}{ Methyl salicylate } & 4.0 & 81.53 & 84.61 & 93.54 & 8.06 & 11.93 & 9.07 & \\
\hline & .5 & 73.14 & 91.43 & 106.57 & 5.88 & 6.15 & 9.91 & .07 \\
\hline \multirow[t]{2}{*}{ Metolachlor } & 4.0 & 81.44 & 86.82 & 92.71 & 3.86 & 8.94 & 9.92 & \\
\hline & .5 & 76.86 & 87.71 & 94.86 & 9.95 & 6.64 & 11.08 & .12 \\
\hline \multirow{2}{*}{ N,N-Diethyl-meta-toluamide (DEET) } & 4.0 & 84.38 & 109.32 & $96.01^{*}$ & 8.91 & 26.67 & 9.62 & \\
\hline & .5 & 77.71 & 98.57 & $71.31^{*}$ & 9.90 & 7.57 & 9.18 & .12 \\
\hline
\end{tabular}


Table 5. Wastewater method mean bias and variability of spike-recovery data for eight replicates with compounds spiked at two concentrations that range from 0.5 to 80 micrograms per liter in reagent-water (including calculated method detection limits), groundwater, and surface-water samples-Continued.

[ $\mu \mathrm{g} / \mathrm{L}$, micrograms per liter; \%, percent; CCV, continuing calibration verification solution; RSD, relative standard deviation; MDL, method detection limit; --, not applicable]

\begin{tabular}{|c|c|c|c|c|c|c|c|c|}
\hline \multirow[b]{2}{*}{ Compound name } & \multirow{2}{*}{$\begin{array}{c}\text { Spike } \\
\text { amount } \\
\text { ( } \mu \mathrm{g} / \mathrm{L})\end{array}$} & \multicolumn{3}{|c|}{ Mean \% recovery } & \multicolumn{3}{|c|}{$\%$ RSD } & \multirow{2}{*}{$\begin{array}{c}\text { Initial } \\
\text { MDL } \\
(\mu \mathrm{g} / \mathrm{L})\end{array}$} \\
\hline & & Reagent & Ground & Surface & Reagent & Ground & Surface & \\
\hline \multirow[t]{2}{*}{ p-Cresol } & 4.0 & 87.91 & 88.96 & 97.54 & 9.95 & 13.77 & 8.82 & \\
\hline & .5 & 81.14 & 99.71 & 118.29 & 6.50 & 6.28 & 11.28 & 0.08 \\
\hline \multirow[t]{2}{*}{ Phenanthrene } & 4.0 & $76.74^{*}$ & $84.39^{*}$ & $83.32^{*}$ & 8.15 & 10.04 & 9.06 & \\
\hline & 0.5 & $68.29^{*}$ & $74.71^{*}$ & $76.43^{*}$ & 6.26 & 7.19 & 11.14 & .07 \\
\hline \multirow[t]{2}{*}{ Phenol } & 4.0 & $68.41^{*}$ & 72.04 & $77.30^{*}$ & 2.87 & 14.59 & 9.62 & \\
\hline & .5 & $64.57^{*}$ & 86.86 & $93.86^{*}$ & 6.14 & 7.26 & 9.09 & .07 \\
\hline \multirow[t]{2}{*}{ Prometon } & 4.0 & 64.03 & 73.00 & 79.32 & 34.10 & 6.40 & 17.04 & \\
\hline & .5 & 70.29 & 81.14 & 92.86 & 7.78 & 6.80 & 11.59 & .08 \\
\hline \multirow[t]{2}{*}{ Pyrene } & 4.0 & 79.59 & $76.77^{*}$ & $81.04^{*}$ & 8.24 & 8.43 & 9.02 & \\
\hline & .5 & 76.29 & $85.03^{*}$ & $79.38^{*}$ & 6.50 & 5.00 & 10.99 & .08 \\
\hline \multirow[t]{2}{*}{ Tri(2-chloroethyl) phosphate } & 4.0 & 77.91 & 85.26 & $79.07^{*}$ & 8.35 & 5.81 & 1.21 & \\
\hline & .5 & 103.10 & 91.77 & $77.80^{*}$ & 5.04 & 4.87 & 4.09 & .08 \\
\hline \multirow{2}{*}{ Tri(dichloroisopropyl) phosphate } & 4.0 & 79.86 & 82.89 & $85.26^{*}$ & 5.40 & 12.28 & 7.85 & \\
\hline & .5 & 74.86 & 88.86 & $64.18^{*}$ & 6.70 & 7.45 & 9.41 & .08 \\
\hline \multirow[t]{2}{*}{ Tributyl phosphate } & 4.0 & 81.81 & 87.21 & 97.79 & 9.02 & 10.18 & 9.91 & \\
\hline & .5 & 76.86 & 96.86 & 181.14 & 8.87 & 6.06 & 9.56 & .11 \\
\hline \multirow[t]{2}{*}{ Triclosan } & 4.0 & 67.63 & 73.54 & $74.70^{*}$ & 8.58 & 9.21 & 7.74 & \\
\hline & .5 & 75.71 & 87.71 & $84.00^{*}$ & 7.99 & 8.27 & 10.54 & .09 \\
\hline \multirow[t]{2}{*}{ Triethyl citrate (ethyl citrate) } & 4.0 & 71.09 & 78.18 & $82.48^{*}$ & 9.37 & 14.37 & 7.85 & \\
\hline & .5 & 66.29 & 82.86 & $77.80^{*}$ & 6.38 & 7.49 & 8.71 & .07 \\
\hline \multirow[t]{2}{*}{ Triphenyl phosphate } & 4.0 & 78.94 & 91.32 & $82.98^{*}$ & 9.26 & 7.79 & 9.36 & \\
\hline & .5 & 75.71 & 99.14 & $82.51^{*}$ & 8.13 & 5.06 & 10.19 & .10 \\
\hline \multirow[t]{2}{*}{ Tri(2-butoxyethyl) phosphate ${ }^{4}$} & 4.0 & 79.81 & $93.98^{*}$ & $169.32^{*}$ & 6.37 & 14.21 & 6.34 & \\
\hline & .5 & 85.43 & $84.11^{*}$ & $164.97^{*}$ & 3.99 & 6.10 & 4.29 & .05 \\
\hline \multicolumn{9}{|c|}{$\begin{array}{l}\text { Compounds with low recovery }{ }^{1} \text {, high variable recovery }(\mathrm{RSD})^{2} \text {, or from a technical mixture }{ }^{3} \\
\text { to be reported with an E remark code (estimated concentration) }\end{array}$} \\
\hline \multirow[t]{2}{*}{ 1-Methylnaphthalene ${ }^{1}$} & 4.0 & 60.53 & 57.50 & 54.29 & 7.53 & 9.80 & 12.84 & \\
\hline & .5 & 44.86 & 49.43 & 68.34 & 4.35 & 8.00 & 5.78 & .03 \\
\hline \multirow[t]{2}{*}{ 1,4-Dichlorobenzene ${ }^{1}$} & 4.0 & 47.16 & 30.25 & 36.82 & 7.16 & 12.77 & 11.01 & \\
\hline & 0.5 & 20.85 & 23.43 & 26.57 & 5.13 & 6.45 & 16.09 & .03 \\
\hline \multirow[t]{2}{*}{ 2,6-Dimethylnaphthalene ${ }^{1}$} & 4.0 & 59.06 & 56.89 & 60.57 & 8.23 & 8.85 & 11.30 & \\
\hline & .5 & 37.43 & 41.71 & 47.71 & 7.99 & 9.76 & 15.58 & .05 \\
\hline \multirow[t]{2}{*}{ 2-Methylnaphthalene ${ }^{1}$} & 4.0 & $54.81^{*}$ & 52.43 & $56.75^{*}$ & 7.83 & 9.89 & 11.72 & \\
\hline & .5 & $40.04^{*}$ & 45.43 & $48.86^{*}$ & 4.74 & 7.17 & 12.33 & .03 \\
\hline \multirow{2}{*}{ 3-tert-Butyl-4-hydroxyanisole (BHA) ${ }^{1}$} & 4.0 & 51.75 & 62.14 & 9.93 & 49.50 & 43.80 & 10.35 & \\
\hline & .5 & 37.14 & 31.67 & 23.00 & 28.80 & 39.43 & 18.10 & .16 \\
\hline \multirow{2}{*}{ 3,4-Dichlorophenyl isocyanate ${ }^{1}$} & 4.0 & 63.41 & 69.43 & $57.78^{*}$ & 11.90 & 10.12 & 10.92 & \\
\hline & .5 & 37.43 & 64.57 & $59.28^{*}$ & 7.99 & 5.28 & 14.24 & .06 \\
\hline beta-Sitosterol $^{1}$ & 16.0 & 21.66 & 109.79 & 90.32 & 40.30 & 30.95 & 35.59 & \\
\hline & 2.0 & 52.07 & 51.86 & 57.29 & 3.30 & 7.59 & 17.94 & .11 \\
\hline
\end{tabular}


Table 5. Wastewater method mean bias and variability of spike-recovery data for eight replicates with compounds spiked at two concentrations that range from 0.5 to 80 micrograms per liter in reagent-water (including calculated method detection limits), groundwater, and surface-water samples-Continued.

[ $\mu \mathrm{g} / \mathrm{L}$, micrograms per liter; \%, percent; CCV, continuing calibration verification solution; RSD, relative standard deviation; MDL, method detection limit; --, not applicable]

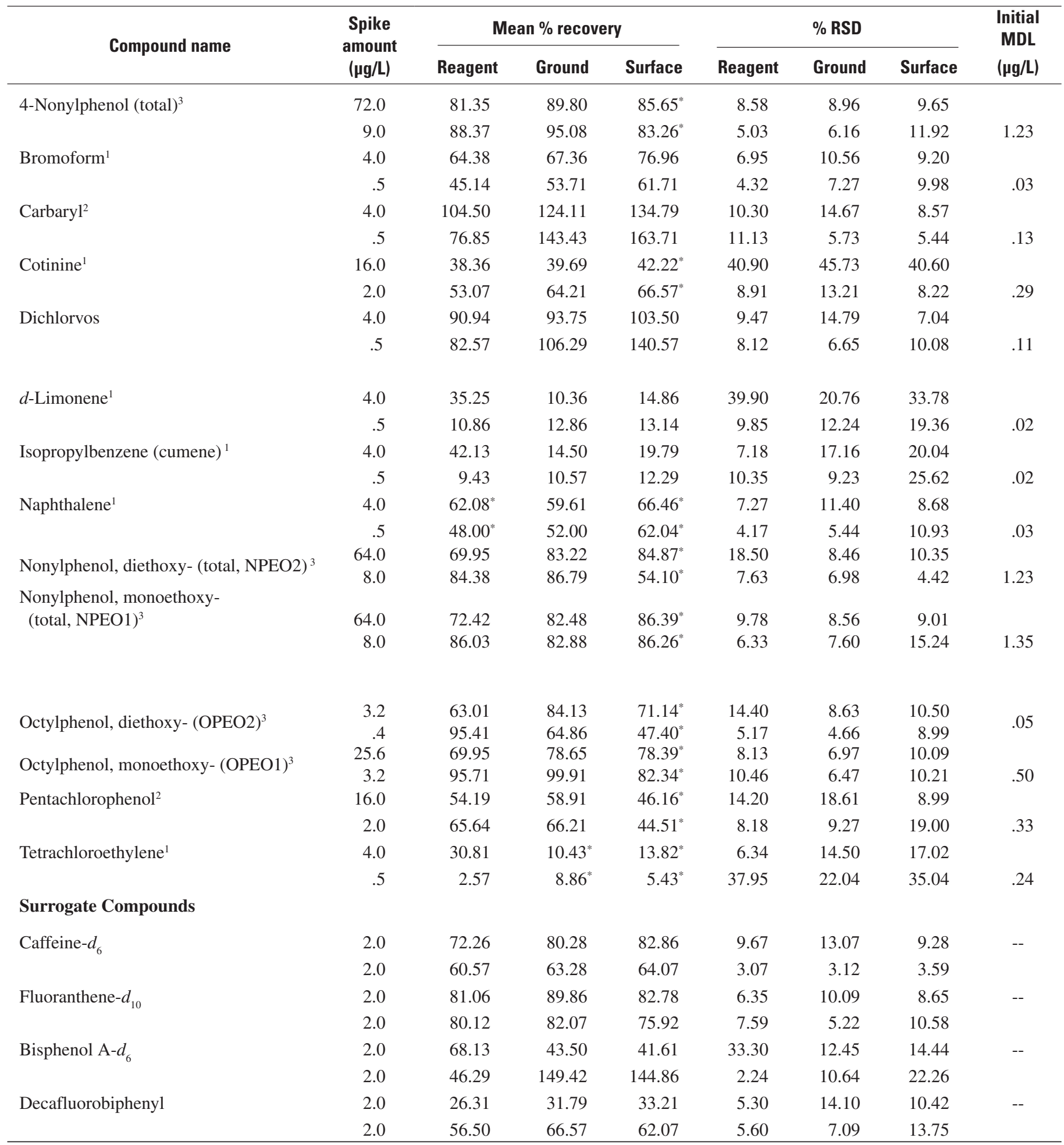

${ }^{1}$ Concentration will be flagged with the "E" remark code because recovery is less than 60 percent or percision is greater than \pm 25 percent RSD.

${ }^{2}$ Concentration will be flagged with the "E" remark code because of unstable instrument response.

${ }^{3}$ Concentration will be flagged with the "E" remark code because the reference standard is from a technical mixture.

${ }^{4}$ Concentration will be flagged with the "E" remark code if the set spike recovery or set CCV concentration is not within control limits (see section 11).

* Percent recovery corrected for background concentration in the unspiked sample. 


\section{Determination of Wastewater Compounds in Whole Water}

Table 6. Wastewater initial method detection limits calculated from the spike-recovery data reported in table 5 using the eight replicate reagent-water samples with compound concentrations that range from 0.5 to 80 micrograms per liter.

[ $\mu \mathrm{g} / \mathrm{L}$, micrograms per liter; RSD, relative standard deviation; MDL, method detection limit; IRL, interim reporting level; --, not calculated]

\begin{tabular}{|c|c|c|c|c|c|}
\hline Compound name & $\begin{array}{c}\text { Spike } \\
\text { amount } \\
\text { ( } \mathrm{\mu g} / \mathrm{L})\end{array}$ & $\begin{array}{c}\text { Mean } \\
\text { recovery } \\
(\mu \mathrm{g} / \mathrm{L})\end{array}$ & $\begin{array}{l}\text { RSD } \\
(\mu \mathrm{g} / \mathrm{L})\end{array}$ & $\begin{array}{l}\text { Initial } \\
\text { MDL } \\
(\mu \mathrm{g} / \mathrm{L})\end{array}$ & $\begin{array}{c}\text { Initial } \\
\text { IRL } \\
\text { ( } \mu \mathrm{g} / \mathrm{L})\end{array}$ \\
\hline 2,2',4,4'-Tetrabromodiphenyl ether & 0.5 & 0.344 & 0.034 & 0.11 & 0.5 \\
\hline 3beta-Coprostanol ${ }^{1}$ & 2.0 & 1.250 & .131 & .38 & 2.0 \\
\hline 3-Methyl-1H-indole (skatol) ${ }^{1}$ & .5 & .409 & .023 & .07 & 1.0 \\
\hline 4-Cumylphenol & .5 & .373 & .041 & .13 & 1.0 \\
\hline 4-n-Octylphenol & .5 & .390 & .037 & .11 & 1.0 \\
\hline 4-tert-Octylphenol & .5 & .419 & .037 & .11 & 1.0 \\
\hline 5-Methyl-1H-benzotriazle ${ }^{1}$ & 2.0 & 1.070 & .112 & .35 & 2.0 \\
\hline Acetophenone $^{1}$ & .5 & .390 & .024 & .07 & .5 \\
\hline $\begin{array}{l}\text { Acetyl-hexamethyl-tetrahydro-naphthalene } \\
(\text { AHTN })^{1}\end{array}$ & .5 & .367 & .037 & .11 & .5 \\
\hline Anthracene ${ }^{1}$ & .5 & .350 & .026 & .08 & .5 \\
\hline Anthraquinone $^{1}$ & .5 & .330 & .026 & .08 & .5 \\
\hline Atrazine $^{1}$ & .5 & .390 & .027 & .08 & .5 \\
\hline Benzo $[a]$ pyrene $^{1}$ & .5 & .373 & .020 & .06 & .5 \\
\hline Benzophenone & .5 & .380 & .032 & .10 & .5 \\
\hline beta-Stigmastanol ${ }^{1}$ & 2.0 & 1.340 & .070 & .22 & 2.0 \\
\hline Bisphenol A & .5 & .232 & .070 & .22 & 1.0 \\
\hline Bromacil & .5 & .353 & .028 & .10 & .5 \\
\hline Caffeine $^{1}$ & .5 & .375 & .020 & .06 & .5 \\
\hline Camphor $^{1}$ & .5 & .358 & .023 & .09 & .5 \\
\hline Carbazole & .5 & .480 & .037 & .12 & .5 \\
\hline Chlorpyrifos & .5 & .393 & .038 & .12 & .5 \\
\hline Cholesterol $^{1}$ & 2.0 & 1.203 & .094 & .30 & 2.0 \\
\hline Diazinon & .5 & .387 & .037 & .11 & .5 \\
\hline Diethylhexyl phthalate (DEHP) & 4.0 & 3.442 & .272 & .85 & 2.0 \\
\hline Diethyl phthalate (DEP) & .5 & .380 & .030 & .10 & .5 \\
\hline Fluoranthene $^{1}$ & .5 & .397 & .026 & .08 & .5 \\
\hline $\begin{array}{l}\text { Hexahydrohexamethyl-cyclo- } \\
\text { pentabenzopyran (HHCB) }\end{array}$ & .5 & .374 & .036 & .11 & .5 \\
\hline Indole $^{1}$ & .5 & .404 & .026 & .08 & .5 \\
\hline Isoborneol $^{1}$ & .5 & .390 & .015 & .05 & .5 \\
\hline Isophorone $^{1}$ & .5 & .396 & .025 & .08 & .5 \\
\hline Isoquinoline $^{1}$ & .5 & .380 & .029 & .09 & .5 \\
\hline
\end{tabular}


Table 6. Wastewater method initial detection limits calculated from the spike-recovery data reported in table 5 using the eight replicate reagent-water samples with compound concentrations that range from 0.5 to 80 micrograms per liter-Continued.

[ $\mu \mathrm{g} / \mathrm{L}$, micrograms per liter; RSD, relative standard deviation; MDL, method detection limit; IRL, interim reporting level; --, not calculated]

\begin{tabular}{|c|c|c|c|c|c|}
\hline Compound name & $\begin{array}{c}\text { Spike } \\
\text { amount } \\
\text { ( } \mu \mathrm{g} / \mathrm{L})\end{array}$ & $\begin{array}{c}\text { Mean } \\
\text { recovery } \\
\text { ( } \mu \mathrm{g} / \mathrm{L})\end{array}$ & $\begin{array}{c}\text { RSD } \\
(\mu \mathrm{g} / \mathrm{L})\end{array}$ & $\begin{array}{c}\text { Initial } \\
\text { MDL } \\
(\mu \mathrm{g} / \mathrm{L})\end{array}$ & $\begin{array}{c}\text { Initial } \\
\text { IRL } \\
(\mu \mathrm{g} / \mathrm{L})\end{array}$ \\
\hline Menthol $^{1}$ & 0.5 & 0.380 & 0.017 & 0.05 & 0.5 \\
\hline Metalaxyl & .5 & .396 & .041 & .13 & .5 \\
\hline Methyl salicylate ${ }^{1}$ & .5 & .366 & .021 & .07 & .5 \\
\hline Metolachlor & .5 & .385 & .038 & .12 & .5 \\
\hline N,N-Diethyl-meta-toluamide (DEET) & .5 & .389 & .038 & .12 & .5 \\
\hline$p$-Cresol ${ }^{1}$ & .5 & .406 & .026 & .08 & 1.0 \\
\hline Phenanthrene $^{1}$ & .5 & .341 & .021 & .07 & .5 \\
\hline Phenol $^{1}$ & .5 & .323 & .023 & .07 & .5 \\
\hline Prometon $^{1}$ & .5 & .351 & .027 & .08 & .5 \\
\hline Pyrene $^{1}$ & .5 & .381 & .025 & .08 & .5 \\
\hline Tri(2-chloroethyl) phosphate ${ }^{1}$ & .5 & .515 & .026 & .08 & .5 \\
\hline Tri(dichloroisopropyl) phosphate ${ }^{1}$ & .5 & .363 & .016 & .05 & .5 \\
\hline Tributyl phosphate & .5 & .384 & .034 & .11 & .5 \\
\hline Triclosan $^{1}$ & .5 & .378 & .030 & .09 & 1.0 \\
\hline Triethyl citrate (ethyl citrate) ${ }^{1}$ & .5 & .331 & .021 & .07 & .5 \\
\hline Triphenyl phosphate & .5 & .427 & .017 & .10 & .5 \\
\hline Tri(2-butoxyethyl) phosphate ${ }^{1}$ & .5 & .517 & .067 & .05 & .5 \\
\hline
\end{tabular}

Compounds with low recovery, high variable recovery (RSD), or from a

technical mixture to be reported with an E remark code (estimated concentration)

\begin{tabular}{|c|c|c|c|c|}
\hline 1-Methylnaphthalene ${ }^{1}$ & .5 & .224 & .010 & .03 \\
\hline 1,4-Dichlorobenzene ${ }^{1}$ & .5 & .224 & .010 & .03 \\
\hline 2,6-Dimethylnaphthalene ${ }^{1}$ & .5 & .187 & .015 & .05 \\
\hline 2-Methylnaphthalene ${ }^{1}$ & .5 & .206 & .010 & .03 \\
\hline $\begin{array}{l}\text { 3-tert-Butyl-4-hydroxyanisole } \\
\text { (BHA) }\end{array}$ & .5 & .186 & .053 & .16 \\
\hline 3,4-Dichlorophenyl isocyanate ${ }^{1}$ & .5 & .187 & .014 & .06 \\
\hline 4-Nonylphenol (total) ${ }^{1}$ & 9.0 & 7.953 & .396 & 1.23 \\
\hline beta-Sitosterol $^{1}$ & 2.0 & 1.041 & .034 & .11 \\
\hline Bromoform $^{1}$ & .5 & .226 & .010 & .03 \\
\hline Carbaryl & .5 & .384 & .043 & .13 \\
\hline Cotinine $^{1}$ & 2.0 & 1.061 & .095 & .29 \\
\hline Dichlorvos & .5 & .413 & .034 & .11 \\
\hline$d$-Limonene $^{1}$ & .5 & .054 & .005 & .02 \\
\hline Isopropylbenzene (cumene) ${ }^{1}$ & .5 & .047 & .005 & .02 \\
\hline Naphthalene $^{1}$ & .5 & .240 & .010 & .03 \\
\hline $\begin{array}{l}\text { Nonylphenol, diethoxy- } \\
\text { (total, NPEO2) }^{1}\end{array}$ & 8.0 & 6.750 & .412 & 1.23 \\
\hline $\begin{array}{l}\text { Nonylphenol, monoethoxy- } \\
\text { (total, NPEO1) }^{1}\end{array}$ & 8.0 & 6.882 & .435 & 1.35 \\
\hline
\end{tabular}


Table 6. Wastewater method initial detection limits calculated from the spike-recovery data reported in table 5 using the eight replicate reagent-water samples with compound concentrations that range from 0.5 to 80 micrograms per liter-Continued.

$[\mu \mathrm{g} / \mathrm{L}$, micrograms per liter; RSD, relative standard deviation; MDL, method detection limit; IRL, interim reporting level; --, not calculated]

\begin{tabular}{|c|c|c|c|c|c|}
\hline Compound name & $\begin{array}{c}\text { Spike } \\
\text { amount } \\
\text { ( } \mu \mathrm{g} / \mathrm{L} \text { ) }\end{array}$ & $\begin{array}{c}\text { Mean } \\
\text { recovery } \\
(\mu \mathrm{g} / \mathrm{L})\end{array}$ & $\begin{array}{c}\text { RSD } \\
(\mu \mathrm{g} / \mathrm{L})\end{array}$ & $\begin{array}{l}\text { Initial } \\
\text { MDL } \\
(\mu \mathrm{g} / \mathrm{L})\end{array}$ & $\begin{array}{c}\text { Initial } \\
\text { IRL } \\
(\mu \mathrm{g} / \mathrm{L})\end{array}$ \\
\hline Octylphenol, diethoxy- $(\mathrm{OPEO} 2)^{1}$ & 0.4 & 0.382 & 0.014 & 0.05 & 1.0 \\
\hline Octylphenol, monoethoxy- $(\mathrm{OPEO} 1)^{1}$ & 3.2 & 3.062 & .159 & .50 & 1.0 \\
\hline Pentachlorophenol $^{1}$ & 2.0 & 1.313 & .107 & .33 & 2.0 \\
\hline Tetrachloroethylene $^{1}$ & 4.0 & 1.220 & .078 & .24 & .5 \\
\hline
\end{tabular}

${ }^{1}$ The compound was fortified at a concentration that was higher than five times the calculated MDL. Therefore, the MDL has been defined as an estimated MDL.

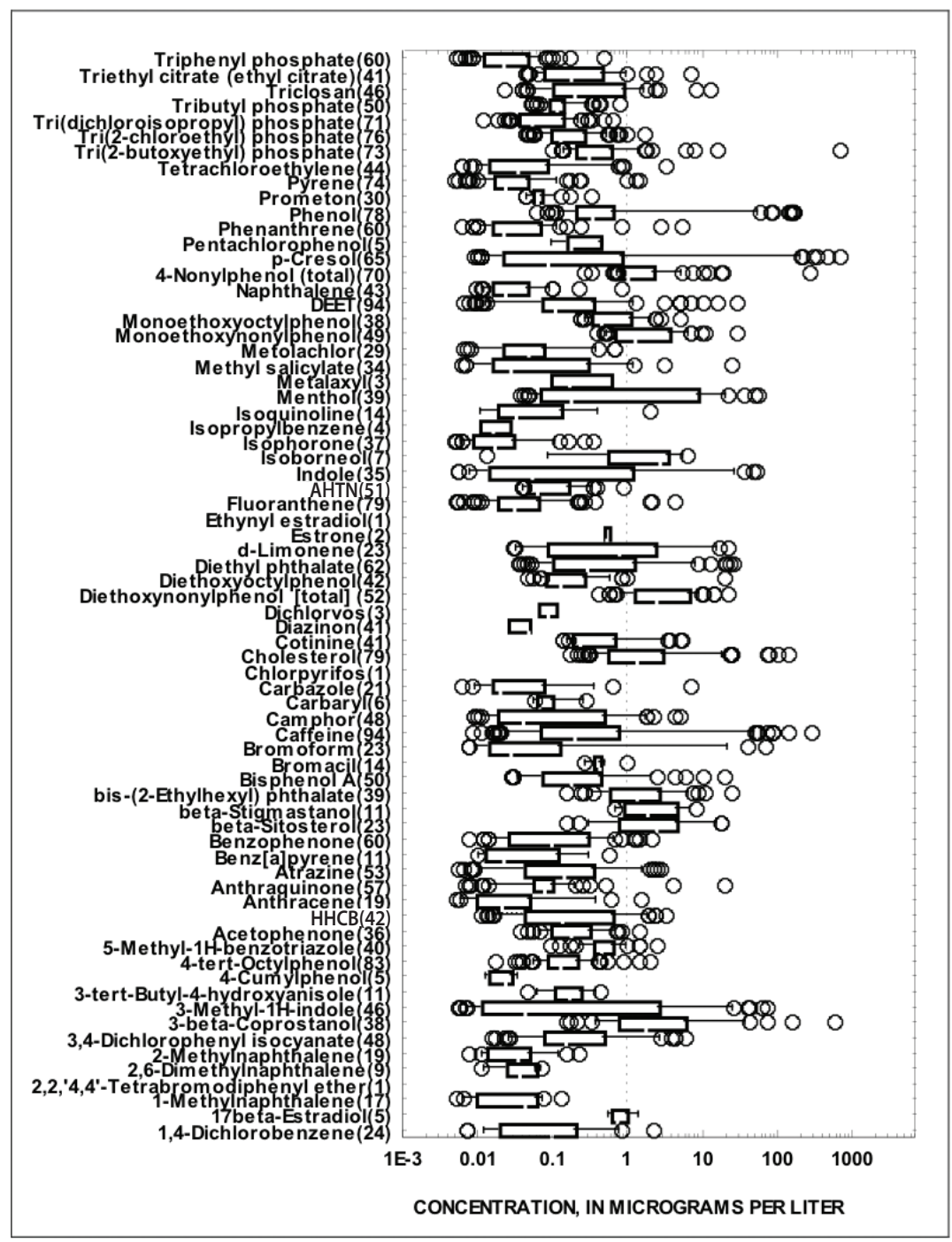

Figure 3. Results for analysis of 140 environmental whole-water samples. The compounds are listed in reverse alphabetical order. The concentration axis is in log scale to accommodate the large concentration ranges for the compounds of interest. The number of samples in which the compound was detected is listed after each compound name in parenthesis.

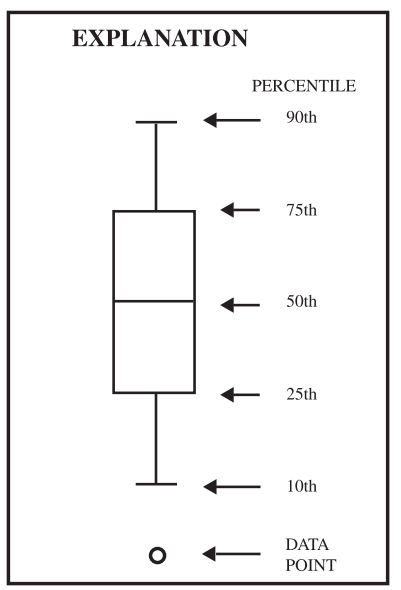


extraction method compare well with the National Water Quality Laboratory's filtered-water solid-phase extraction waste-water method.

The assessment of fate and transport for these emerging contaminants also is possible with the development of a complementary sediment waste indicator method at the NWQL.

The high frequency of compounds that have been detected for the previous 8 years (1998-2005) has demonstrated the capability of this method for identifying anthropogenic contaminants over a wide range of sample matrices. Many method compounds are recognized endocrine-system disrupters (alkylphenols, alkylphenol polyethoxylates, and bisphenol A, for example), whereas others, such as caffeine, musk fragrances, and fecal sterols, are excellent indicators of wastewater.

\section{References Cited}

Barber, L.B., Brown, G.K., and Zaugg, S.D., 2000, Potential endocrine disrupting organic chemicals in treated municipal wastewater and river water: Analysis of environmental endocrine-disruptors, American Chemical Society Symposium Series 747, p. 97-123.

Blackburn, M.A., and Waldock, M.J., 1995, Concentrations of alkylphenols in rivers and estuaries in England and Wales: Water Resources, Elsevier Science, v. 29, no. 7, p. 1623-1629.

de Boer, J., Wester, P.G., Pastor i Rodriguez, D., Lewis, W.E., Boon, J.P., 1998, Polybrominated biphenyls and diphenylethers in sperm whales and other marine mammals-A new threat to ocean life?: Organohalogen Compounds, v. 35, p. 383-386.

Brown, G.K., Zaugg, S.D., and Barber, L.B., 1999, Wastewater analysis by gas chromatography/mass spectrometry: U.S. Geological Survey Toxic Substances Hydrology Program Proceedings of the Technical Meeting, March 8-12, Charleston, South Carolina, p. 431-435.

Burkhardt, M.R., Zaugg, S.D., Smith, S.G., and ReVello, R.C., 2006, Determination of wastewater compounds in sediment and soil by pressurized solvent extraction, solid-phase extraction, and capillary-column gas chromatography/mass spectrometry: U.S. Geological Survey Techniques and Methods, book 5, chap. B2, 40 p.

Castro, R., Natera, R., Benitez, P., and Barroso, C.G., 2004, Comparative analysis of volatile compounds of 'fino' sherry wine by rotatory and continuous liquid-liquid extraction and solid-phase microextraction in conjunction with gas chromatography-mass spectrometry: Analytica Chemica Acta, v. 513, p. 141-150.

ChemFinder Webserver, 2006, Database and internet searching: World Wide Web accessed January 17, 2006, at http://chemfinder.camsoft.com
Childress, C.J.O., Foreman, W.T., Connor, B.F., and Maloney, T.J, 1999, New reporting procedures based on long-term method detection levels and some considerations for interpretations of water-quality data provided by the U.S. Geological Survey National Water Quality Laboratory: U.S. Geological Survey Open-File Report 99-193, 19 p.

Colburn, J., Dumanoski, D., Myers, J.P., 2000, Our stolen future website: World Wide Web accessed January 17, 2006, at www.ourstolenfuture.org/Basics/chemlist.htm

EXtension TOXicology NETwork, 2006, EXTOXNET InfoBase: World Wide Web accessed January 17, 2006, at http://ace.orst.edu/info/extoxnet

Fishman, M.J., 1993, Methods of analysis by the U.S. Geological Survey National Water Quality LaboratoryDetermination of inorganic and organic constituents in water and fluvial sediments: U.S. Geological Survey OpenFile Report 93-125, 217 p.

Geiger, W., Brunner, P.H., and Schaffner, C., 1984, 4Nonylphenol in sewage sludge: Accumulation of toxic metabolites from nonionic surfactants: Science, v. 225, p. 623-625.

HealthCentral.com, 2006, RxList, the internet drug index: World Wide Web accessed January 17, 2006, at http://www. rxlist.com

Jha, V.K., and Wydoski, D.S., 2003, Methods of analysis by the U.S. Geological Survey National Water Quality Laboratory-Determination of organophosphate pesticides in whole water by continuous liquid-liquid extraction and capillary-column gas chromatography with flame photometric detection: U.S. Geological Survey Water-Resources Investigations Report 03-4139, 26 p.

Jin, X., Jiang, G., Huang, G., Liu, J., and Zhou, Q., 2004, Determination of 4-tert-octylphenol, 4-nonylphenol, and bisphenol A in surface waters from the Haihe River in Tianjin by gas chromatography-mass spectrometry with selected ion monitoring: Chemosphere, v. 56, p. 1113-1119.

Jobling, S.J., and Sumpter, J.P., 1993, Detergent compounds in sewage effluent are weakly oestrogenic to fish-An in vivo study using rainbow trout hepatocytes: Aquatic Toxicology, v. 27 , p. $361-372$.

Kolpin, D.W., Furlong, E.T., Meyer, M.T., Thurman, E.M., Zaugg, S.D., Barber, L.B., Buxton, H.T., 2002, Pharmaceuticals, hormones, and other organic wastewater contaminants in U.S. streams, 1999-2000-A national reconnaissance: Environmental Science \& Technology, v. 36, p. 1202-1211.

Maloney, T.J., ed., 2005, Quality management system, U.S. Geological Survey National Water Quality Laboratory: U.S. Geological Survey Open-File Report 2005-1263, version 1.3, 9 November 2005, accessed January 11, 2006, at http://pubs.usgs.gov/of/2005/1263/ 
National Institute of Standards and Technology, 2006, NIST chemistry WebBook: World Wide Web accessed January 17, 2006, at http://webbook.nist.gov

National Toxicology Program, 2006, Chemical health and safety data: World Wide Web accessed March 22, 2006, at URL http://ntp.niehs.nih.gov/

Paxéus, N., Robinson, P., and Balmér, P., 1992, Study of organic pollutants in municipal wastewater in Göteborg, Sweden: Water Science Technology, v. 25, no. 11, p. 245-256.

Sandstrom, M.W., Stroppel, M.E., Foreman, W.T., and Schroeder, M.P., 2001, Methods of analysis by the U.S. Geological Survey National Water Quality Laboratory-Determination of moderate-use pesticides and selected degradates in water by $\mathrm{C}-18$ solid-phase extraction and gas chromatography/mass spectrometry: U.S. Geological Survey Water-Resources Investigations Report 01-4098, 70 p.

Sandstrom, M.W., Kolpin, D.W., Thurman, E.M. and Zaugg, S.D., 2005, Widespread detection of N,N-diethyl- $m$-toluamide (DEET) in U.S. streams: Comparison with concentrations of pesticides, personal care products, and other organic wastewater compounds: Environmental Toxicology and Chemistry, v. 24, no. 5, p. 1029-1034.

Shigenaka, G., and Price, J.E.,1988, Correlation of coprostanol to organic contaminants in coastal and estuarine sediments of the U.S.: Water Resources Bulletin, v. 24, no. 5, p. 989-998.

Spectrum Laboratories, Inc., 2006, Compound list: World Wide Web accessed January 17, 2006, at http://www. speclab.com/compound/chemabc.htm

Timme, P.J., 1995, National Water Quality Laboratory 1995 services catalog: U.S. Geological Survey Open-File Report 95-352, $92 \mathrm{p}$.

U.S. Environmental Protection Agency, 1995, Methods for organic chemical analysis of municipal and industrial wastewaters: U.S. Code of Federal Regulations, Title 40, Parts 136-149.

U.S. Environmental Protection Agency, 1996, Thirty-seventh report of the Toxic Substances Control Act Interagency Testing Committee to the Administrator: Federal Register, v. 61, no. 23, Feb. 2, 1996, p. 4188-4196.

U.S. Environmental Protection Agency, 1997a, Special report on environmental endocrine disruption: An effects assessment and analysis: EPA/630/R-96/012, February 1997, 111 p.

U.S. Environmental Protection Agency, 1997b, Guidelines establishing test procedures for the analysis of pollutants (App. B, Part 136, Definition and procedures for the determination of the method detection limit): U.S. Code of Federal Regulations, Title 40, revised as of July 1, 1997, p. 265-267.

U.S. Environmental Protection Agency, 2005, EPI-suite website: World Wide Web accessed January 17, 2006, at www.epa.gov/opptintr/exposure/docs/episuite.htm
U.S. Geological Survey, variously dated, National field manual for the collection of water-quality data: U.S. Geological Survey Techniques of Water-Resources Investigations, book 9, chaps. A1 through A6, available online at http://pubs. water.usgs.gov/twri9A

U.S. Geological Survey, 2003, Codes used in water-quality processing system (Appendix A of 4 appendixes), table 17: U.S. Geological Survey National Water Information System, accessed February 1, 2006, at URL http://wwwnwis.er.usgs. gov/nwisdocs4_3/qw/QW-AppxA.pdf

U.S. Geological Survey, 2005, Revision of the procedure for requesting laboratory matrix spikes: U.S. Geological Survey National Water Quality Laboratory Technical Memorandum No. 05.02, accessed January 17, 2006, at http://nwql.usgs. gov/Public/tech_memos/nwql.2005-02.html

Ward, J.R., and Harr, C.A., eds., 1990, Methods for collection and processing of surface-water and bed-material samples for physical and chemical analyses: U.S. Geological Survey Open-File Report 90-140, 71 p.

Wershaw, R.L., Fishman, M.J., Grabbe, R.R., and Lowe, L.E., eds., 1987, Methods for the determination of organic substances in water and fluvial sediments: U.S. Geological Survey Techniques of Water-Resources Investigations, book 5, chap. A3, 80 p.

Wilde, F.D., Radtke, D.B., Gibs, Jacob, and Iwatsubo, R.T., eds., April 2004, Processing of water samples (version 2.1): U.S. Geological Survey Techniques of Water-Resources Investigations, book 9, chap. A5, accessed January 11, 2006, at http://pubs.water.usgs.gov/twri9A5/ (Separate updates for 5.6.1.F, "Wastewater, pharmaceutical, and antibiotic compounds," 5.6.4A, "Arsenic speciation," and 5.6.4.B, "Lowlevel mercury" are provided on the Web page.)

Wilde, F.D., April 2004, Cleaning of equipment for water sampling (version 2.0): U.S. Geological Survey Techniques of Water-Resources Investigations, book 9, chap. A3, accessed January 11, 2006, at http://pubs.water.usgs.gov/twri9A3/

Wilkison, D.H., Armstrong, D.J., and Blevins, D.W., 2002, Effects of wastewater and combined sewer overflow on water quality in the Blue River Basin, Kansas City, Missouri and Kansas, July 1998-October 2000: U.S. Geological Survey Water-Resources Investigations Report 02-4107, 162 p.

Wingfors, H., Hansson, M., Päpke, O., Bergek, S., Nilsson, C., and Haglund, P., 2005, Sorbent-assisted liquid-liquid extraction (Chem-Elut) of polychlorinated biphenyls, dibenzo$p$-dioxins and dibenzofurans in the lipid fraction of human blood plasma: Chemosphere, v. 58, p. 311-320.

Zaugg, S.D., Smith, S.G., Schroeder, M.P., Barber, L.B., and Burkhardt, M.R., 2002, Methods of analysis by the U.S. Geological Survey National Water Quality LaboratoryDetermination of wastewater compounds by polystyrenedivinylbenzene solid-phase extraction and capillary-column gas chromatography/mass spectrometry: U.S. Geological Survey Water-Resources Investigations Report 01-4186, 37 p. 


\section{Glossary}

C

\section{Continuing calibration verification}

(CCV) A standard solution that contains method compounds and is used to determine the bias of the present calibration curve for the method compounds. The CCV is an instrumental standard only and is not processed through preparative steps of the method.

\section{I}

Interim reporting level (IRL) A temporary reporting level used for new or custom methods when long-term method detectionlevel data are unavailable and a laboratory reporting level has not yet been established (U.S. Geological Survey, 2003).

Internal standard (IS A compound not expected to be found in any environmental sample that is added to every sample extract in a known amount. The internal standard is used to measure the relative gas chromatographic/mass spectrometric (GC/MS) responses of other compounds and surrogates in each sample.

\section{L}

Long-term method detection level (LTMDL) The minimum concentration of a substance that can be identified, measured, and reported with 99-percent confidence that the compound concentration is greater than zero. The LT-MDL is calculated from replicate analyses of samples fortified with all the method compounds, and includes precision introduced by multiple instruments, multiple analysts, and multiple calibrations from 6 to 12 months (Childress and others, 1999).
M

Method detection limit (MDL) The minimum concentration of a substance that can be measured and reported with 99-percent confidence that the compound concentration is greater than zero (U.S. Environmental Protection Agency, 1997b). The MDL is calculated from at least seven replicate analyses of samples fortified with all the method compounds. The MDL is used to establish initial minimum reporting levels, until the long-term method detection level can be calculated to include day-to-day precision.

Minimum reporting level (MRL) The lowest measured concentration of a compound that may be reliably reported by using a given analytical method (Timme, 1995).

\section{P}

Procedural internal standard quantitation A quantitation method where the internal standard is added during sample processing prior to transferring the sample extract to a vial. The addition of the procedural internal standard during sample processing compensates for quantitation losses in those processing steps after the internal standard is added.

\section{S}

Surrogate A compound not expected to be found in any environmental sample that is added to every sample in a known amount prior to sample processing. The surrogate is used to monitor method performance for each sample. 
Manuscript approved for publication July 10, 2006

Prepared by the U.S. Geological Survey Publishing Service Center, Denver, Colorado

USGS Publishing Staff

Edited by Jon W. Raese

Report approved by Keith L. Lucey

Cover designed by Suzanne C. Roberts

Report prepared by Margo L. Johnson

\section{Technical Reviews}

Vince Matri, U.S. Environmental Protection Agency

Gregory K. Brown, USGS, Branch of Regional Research

Mark R. Burkhardt, USGS, National Water Quality Laboratory

James A. Lewis, USGS, National Water Quality Laboratory

Peter F. Rogerson, USGS, Office of Water Quality

Donald H. Wilkison, USGS, Missouri Water Science Center

For more information concerning the research in this report, contact:

National Water Quality Laboratory, Chief

U.S. Geological Survey

P.O. Box 25046, MS 407

Denver Federal Center

Denver, Colorado 80225-0046

http://nwql.cr.usgs.gov 

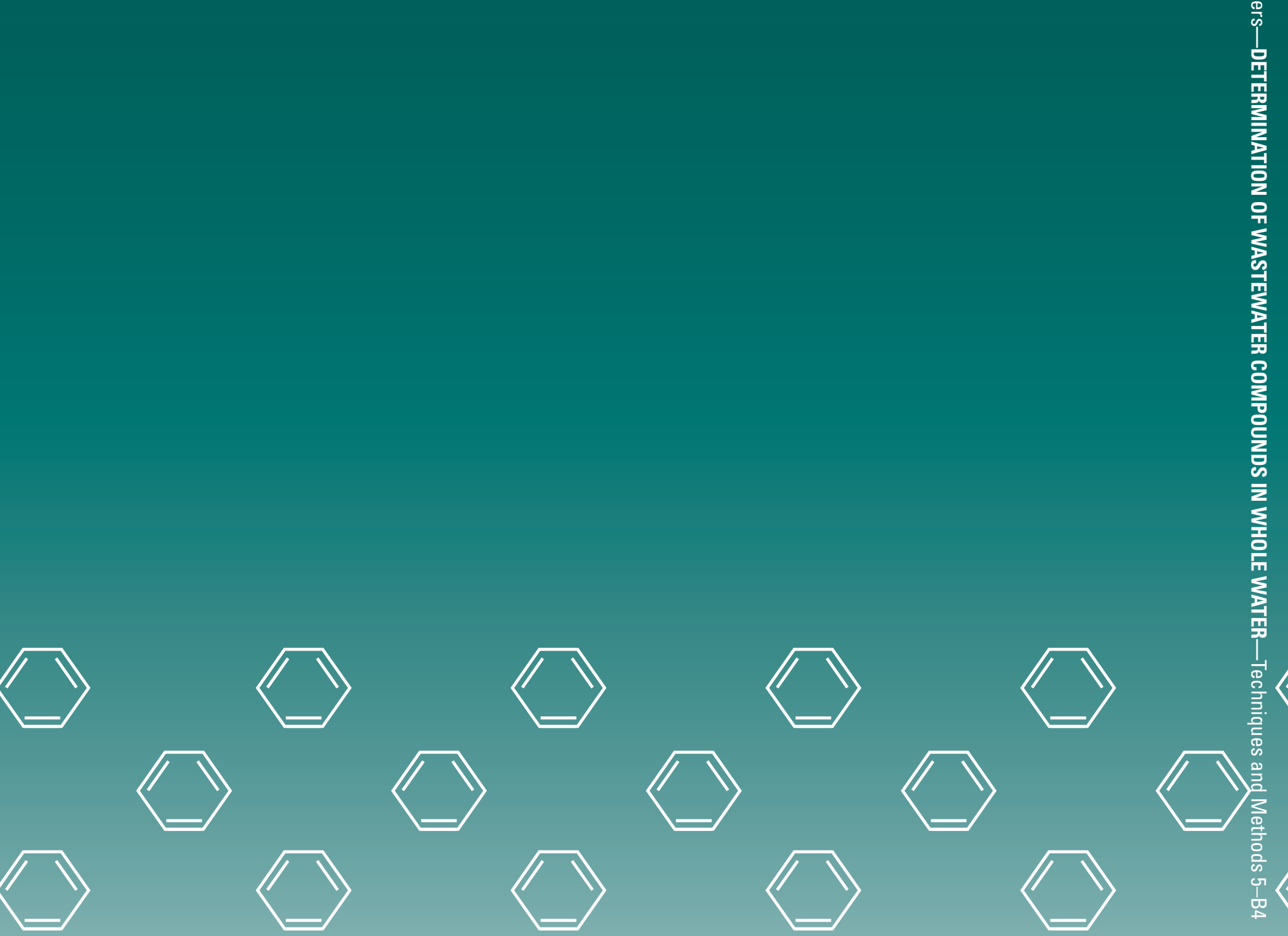

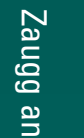

ż

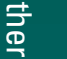

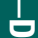
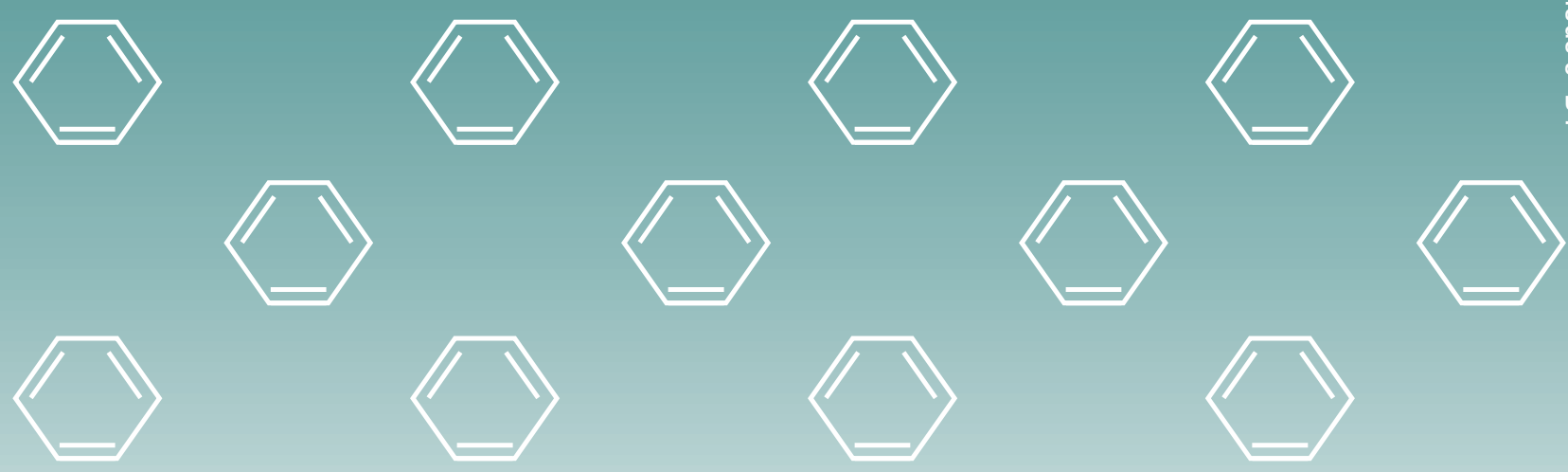

Printed on recycled paper

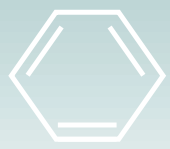

